\title{
Applications of MALDI-TOF mass spectrometry in clinical diagnostic microbiology
}

\author{
Antony Croxatto, Guy Prod'hom \& Gilbert Greub \\ Institute of Microbiology, University Hospital Center and University of Lausanne, Lausanne, Switzerland
}

Correspondence: Gilbert Greub, Institute of Microbiology, University Hospital Center and University of Lausanne, 1011 Lausanne, Switzerland. Tel.: +4121314

49 79; fax: +4121314 40 60;

e-mail: gilbert.greub@chuv.ch

Received 20 April 2011; revised 6 July 2011; accepted 7 July 2011.

Final version published online 22 August 2011.

DOI: $10.1111 / j .1574-6976.2011 .00298 . x$

Editor: Maggie Smith

\section{Keywords}

MALDI-TOF; mass spectrometry; microbial identification; bacteriology; diagnostic microbiology.

\begin{abstract}
Until recently, microbial identification in clinical diagnostic laboratories has mainly relied on conventional phenotypic and gene sequencing identification techniques. The development of matrix-assisted laser desorption ionization time-of-flight mass spectrometry (MALDI-TOF MS) devices has revolutionized the routine identification of microorganisms in clinical microbiology laboratories by introducing an easy, rapid, high throughput, low-cost, and efficient identification technique. This technology has been adapted to the constraint of clinical diagnostic laboratories and has the potential to replace and/or complement conventional identification techniques for both bacterial and fungal strains. Using standardized procedures, the resolution of MALDI-TOF MS allows accurate identification at the species level of most Gram-positive and Gram-negative bacterial strains with the exception of a few difficult strains that require more attention and further development of the method. Similarly, the routine identification by MALDI-TOF MS of yeast isolates is reliable and much quicker than conventional techniques. Recent studies have shown that MALDI-TOF MS has also the potential to accurately identify filamentous fungi and dermatophytes, providing that specific standardized procedures are established for these microorganisms. Moreover, MALDI-TOF MS has been used successfully for microbial typing and identification at the subspecies level, demonstrating that this technology is a potential efficient tool for epidemiological studies and for taxonomical classification.
\end{abstract}

\section{Introduction}

The matrix-assisted laser desorption ionization time-offlight mass spectrometry (MALDI-TOF MS) is a rapid, accurate, and cost-effective method of microbial characterization and identification. This technology generates characteristic mass spectral fingerprints, that are unique signatures for each microorganism and are thus ideal for an accurate microbial identification at the genus and species levels and has a potential to be used for strain typing and identification.

MS has been used for several decades in chemistry but it was in 1975 that Anhalt and Fenselau (Anhalt \& Fenselau, 1975) proposed for the first time that bacterial characterization could be achieved using this technique. They noticed that unique mass spectra were produced from bacterial extracts of different genera and of different species. In the 1980s, the development of desorption/ioniza- tion techniques such as plasma desorption (PD), laser desorption (LD) and fast atom bombardment (FAB) allowed the generation of molecular biomarker ions from microorganisms leading to bacterial profiling (Heller et al., 1987; Platt et al., 1988). In early experiments, only biomarker molecules of low molecular masses such as bacterial lipids were analysed (Shah \& Collins, 1980; Heller et al., 1988), as the processes used for the ionization of biomolecules were too energy rich to avoid unpredictable analyte decomposition. The evolution of soft ionization techniques such as MALDI and electrospray ionization (ESI) developed in the late 1980s (Tanaka \& Fenn, 2002) made possible analysis by MS of large biomolecules such as intact proteins. Several groups (Cain et al., 1994; Girault et al., 1996; Liang et al., 1996) demonstrated that MALDI-TOF could be used to produce protein profiles following cellular extraction and purification. However, Holland et al. (1996) reported for the first 
time in 1996 that MALDI-TOF spectral fingerprints could be obtained from whole bacterial cells without pretreatment before the MS analysis. This approach was then used to identify bacteria at the genus and species levels by multiple research teams (Claydon et al., 1996; Krishnamurthy \& Ross, 1996; Haag et al., 1998; Pribil \& Fenselau, 2005; Pignone et al., 2006; Vargha et al., 2006; Nagy et al., 2009). Since the late 1990s, the success of this technique for the rapid identification of bacteria but also fungi and yeast was demonstrated by an impressive exponential increase in the number of publications concerning MALDI-TOF identification of microorganisms.

MALDI-TOF MS has been used to characterize a wide variety of microorganisms including bacteria, fungi, and viruses (Giebel et al., 2010). The capability of MALDITOF to rapidly characterize microorganisms favors its potential applications in multiple areas including medical diagnostics, biodefense, environmental monitoring, and food quality control. MALDI-TOF MS is suitable for high-throughput and rapid microbial identification at low costs and is an alternative for conventional laboratory biochemical and molecular identification systems.

In this review, we will first present the technical background of the MALDI-TOF MS method including sample preparation, MS, bioinformatics analysis of fingerprint spectra, and their comparison with databases for microorganism identification. We will then present the application of MALDI-TOF MS microbial identification from bacteria and fungi isolates and directly from clinical samples. We will then address the important issues of quality control, maintenance, time-to results, and cost effectiveness. Finally, we will discuss the use of MALDI-TOF MS for additional applications such as microbial taxonomy, typing and identification of virulence factors (Bizzini \& Greub, 2010; Murray, 2010).

\section{Technique}

A mass spectrometer is composed of three functional units, (1) an ion source to ionize and transfer sample molecules ions into a gas phase, (2) a mass analyser that separate ions according to their mass-to-charge ratio $(\mathrm{m} / \mathrm{z})$, and (3) a detection device to monitor separated ions. Several ionization methods have been developed including $\mathrm{PD}, \mathrm{FAB}$, chemical ionization (CI), atmospheric pressure CI, electrospray (ESI), LD, and MALDI. The method of ionization is determined according to the nature of the sample and the goal of the MS analysis, but ESI and MALDI are soft ionization techniques that allow ionization and vaporization of large nonvolatile biomolecules such as intact proteins (Emonet et al., 2010). In contrast to ESI, MALDI generates mostly singly charged ions and thus MALDI derived spectra may include larger numbers of proteins. LD has been successfully coupled to several kinds of mass analysers to characterize microorganisms such as TOF (Lay, 2001), Fourier transform ion cyclotron resonance (Ho \& Fenselau, 1998), quadrupole-TOF (She et al., 2001), and quadrupole ion trap (Meetani et al., 2007). The various operative modes of the different mass analysers confer strengths and weaknesses in their performance characterized by mass accuracy, resolution, mass range, sensitivity, and scan speed and cost (Table S1) (Jonsson, 2001; Aebersold \& Mann, 2003; Domon \& Aebersold, 2006; Graham et al., 2007). The performance of mass analysers can be improved by combining and/or summing the advantages of one sort of analyser (tandem MS) or of different analysers (hybrid MS) through the development of multistage instruments such as hybrid quadrupole TOF (Q-Q-TOF), tandem TOF (TOF-TOF), and triple quadrupole (Domon \& Aebersold, 2006). Overall, the required performance expected form a mass analyser depends on the type of sample to be analysed (complex/simple mixtures, proteins, peptides, lipids, and polysaccharides) and the ultimate goal of the analysis (quantification, protein identification, microorganism identification, and biotyping).

TOF mass analysers (Cotter, 1997) have been used for intact microorganisms detection for many years (Heller et al., 1987), because they are suited for interfacing with pulse laser ionization and offer the possibility of rapid analysis and miniaturization.

In MALDI analysis, samples are prepared by mixing the samples with a matrix which results in the crystallization of the sample within the matrix. The matrix is composed of small acid molecules that have a strong optical absorption in the range of the laser wavelength used. The matrix composition varies according to the biomolecule to be analysed and the type of laser used (Fenselau \& Demirev, 2001). The most frequently used matrices are 2,5-dihydroxybenzoic acid (DHB), $\boldsymbol{\alpha}$-cyano4-hydroxycinnamic acid (CHCA), sinapinic acid (SA), ferulic acid (FA), and 2,4-hydroxy-phenyl benzoic acid. FA, SA, and CHCA have been shown to be effective for the detection of proteins biomarkers (Fenselau \& Demirev, 2001; Vaidyanathan et al., 2002; Williams et al., 2003), whereas DHB appears to be the best choice for the detection of glycopeptides and glycoproteins (Giebel et al., 2010). The size and the intensities of the peaks of the detected molecules are dependent on the matrix selected for the experiment. DHB and CHCA are usually optimal for the detection of lower mass ions (Hathout et al., 2000; Williams et al., 2003; Ruelle et al., 2004) with a detection up to $10 \mathrm{kDa}$ when the proper solvent is used. Both SA and FA have been shown to be better for the detection of higher mass ions (above $15 \mathrm{kDa}$ ) (Madonna et al., 2000; Conway et al., 2001; Ruelle et al., 
2004; Vargha et al., 2006) but provide a lower sensitivity than CHCA (Wang et al., 1998; Ruelle et al., 2004).

Intact microorganisms can be directly processed to MALDI-TOF without pretreatment because most vegetative bacteria are lysed following exposure to water, organic solvent and/or strong acid in the MALDI matrix. When resistant microrganims such as some viruses, bacterial spores, and yeast cells have to be analysed by MALDI, strong organic acids and/or alcohols are usually added in pretreatment steps. Similarly, for some bacterial species (such as the Actinomyces), specific pretreatment or protein extraction procedures may be useful (Bizzini et al., 2011).

The marked differences in bioanalytes fingerprints observed with the different matrix demonstrate that similar standardized preanalytical and analytical procedures than those performed to establish a database must be followed to ensure accurate identification. This implies that any modification of the procedure (1) should conformed to the manufacturer's recommendations, (2) should be analysed to demonstrate that protein profiles remained consistent with database fingerprints or (3) should use a new database created with the modified protocol.

In practice, a microbial sample is mixed with a matrix on a conductive metal plate. The mixture can be deposited on the metal support or alternatively the microbial sample is deposited and dried out on the support before the addition of the matrix. After the crystallization of the matrix and compound, the target on the metal plate is introduced in the mass spectrometer where it is bombarded with brief laser pulses from usually a nitrogen laser (Fig. 1). The matrix absorbs energy from the laser leading to the desorption of the analytes that are then vaporized and ionized in the gas phase. This matrixassisted desorption and ionization of the analytes leads to the formation of predominantly singly charged sample ions. The desorbed and ionized molecules are first accelerated through an electrostatic field and are then ejected through a metal flight tube that is subjected to a vacuum until they reach a detector, with smaller ions traveling faster than larger ions. The TOF required to reach the detector is dependent on the mass $(\mathrm{m})$ and charge $(z)$ of the bioanalyte and is proportional to the square root of $\mathrm{m} / \mathrm{z}$. Thus, bioanalytes with different $\mathrm{m} / \mathrm{z}$ that composed a complex sample are separated according to their TOF and create a mass spectrum that is characterized by both the $m / z$ and the intensity of the ions, which is the number of ions of a particular $\mathrm{m} / \mathrm{z}$ that struck the detector. The results of a spectral signature is composed of spikes ranging usually from 1000 to $20000 \mathrm{~m} / z$. Usually, MALDI produces single charged $(z=1)$ ions and thus the $\mathrm{m} / \mathrm{z}$ of an analyte corresponds to the value of its mass.

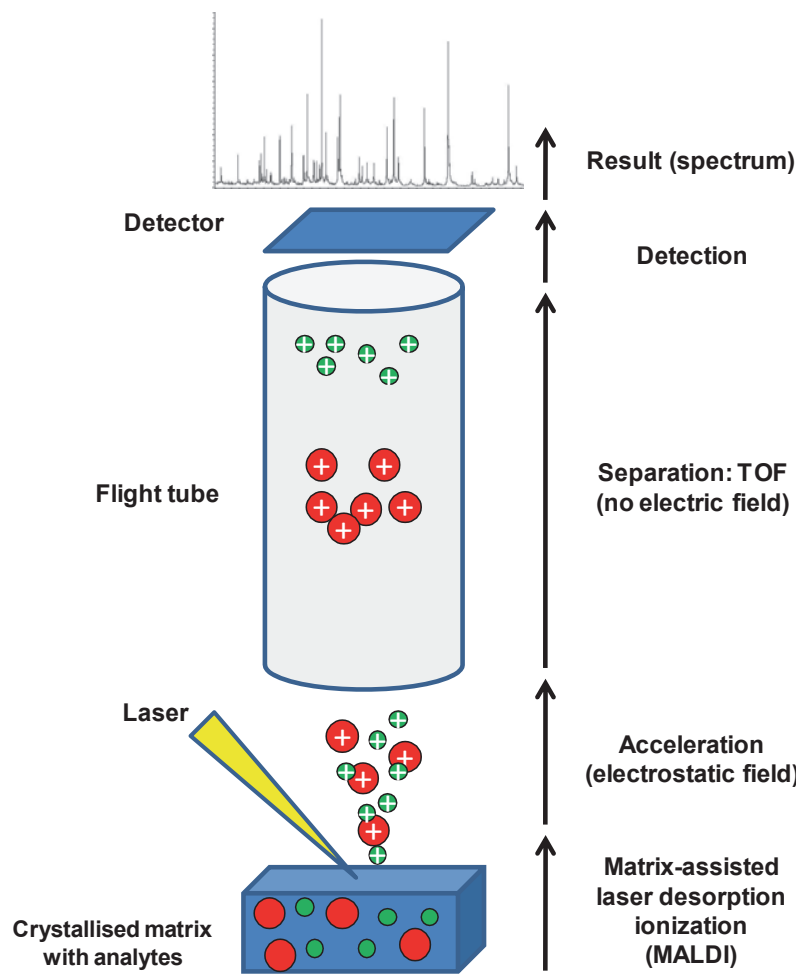

Fig. 1. Technical description of MALDI-TOF MS. The sample is mixed with a matrix on a conductive metal plate. After crystallization of the matrix and microbial material, the metal plate is introduced in the mass spectrometer and is bombarded with brief laser pulses. The desorbed and ionized molecules are accelerated through an electrostatic field and ejected through a metal flight tube subjected to vacuum until they reach a detector, with smaller ions traveling faster than larger ions. Thus, bioanalytes separated according to their TOF create a mass spectrum that is composed by mass to charge ratio $(\mathrm{m} / \mathrm{z})$ peaks with varying intensities. A spectrum is thus a microbial signature that is compared with a database for the identification at the species or genus level.

\section{Data analysis}

\section{Biomarkers}

Several research groups have demonstrated that biomolecules desorbed from whole unfractionated cells and detected above $4 \mathrm{kDa}$ are intact proteins (Arnold et al., 1999; Dai et al., 1999; Holland et al., 1999; Ryzhov \& Fenselau, 2001). Most of the biomarkers detected in MALDI-TOF spectra of intact bacterial cells have a molecular mass below $15 \mathrm{kDa}$. A thorough characterization of MALDI biomarkers performed on intact Escherichia coli cells have demonstrated that the MALDI detected biomolecules corresponds to proteins from the inside of bacterial cell that are abundant, basic, and of medium hydrophobicity (Ryzhov \& Fenselau, 2001). 
Among these MALDI-detected proteins, about half matched ribosomal proteins that are abundant and very basic (Arnold et al., 1999; Ryzhov \& Fenselau, 2001), which is a biochemical trait favorable for efficient ionization during the MALDI process (Krause et al., 1999). Thus, the abundance (more than $20 \%$ of total cell proteins) and the basic nature of ribosomal proteins explain why the majority of the peaks detected in a MALDI-TOF spectrum correspond to ribosomal proteins. In addition, the lysis of bacterial cells in organic solvents and in acidic conditions favoring the extraction of ribosomal proteins combined with the utilization of a specific matrix allowed the development of a method leading to the ionization of mainly ribosomal proteins (Suh \& Limbach, 2004).

In a study performed by Ryzhov \& Fenselau (2001) on E. coli to characterize the nature of the proteins favored by MALDI, several additional groups of proteins than ribosomal proteins were identified. These also included abundant nucleic acid-binding proteins, such as E. coli DNA-binding protein $\mathrm{HU} \alpha$ - and $\beta$-subunits (DbhA and DbhB, respectively) and cold-shock proteins, such as cold-shock proteins A, C, and E (CspA, CspC, and CspE). Similar to ribosomal proteins, these protein families are highly abundant, basic, and of medium hydrophobicity. Holland et al. (1999) potentially identified the acid-resistant precursor proteins $\mathrm{HdeA}$ and $\mathrm{HdeB}$ observed in the MALDI analysis of both intact E. coli and Shigella flexneri. The ion at $m / z 7643$ in the spectra from Pseudomonas aeruginosa was mapped to the cold-shock protein CspA and similarly the ion at $\mathrm{m} / \mathrm{z} 7684$ observed in Pseudomonas putida was identified as the cold-acclimation protein CapB (Fenselau \& Demirev, 2001). Sun et al. (2006) have selected in the MALDI-TOF spectra of Lactobacillus plantarum 34 reliable biomarkers including 31 ribosomal subunit proteins and three ribosome-associated proteins identified as a small heat shock protein, a methylase and the DNA-binding protein II. A comprehensive study was published by Dieckmann et al. (2008) where protein identities were assigned to biomarker peaks obtained by whole-cell MALDI-TOF MS of salmonellae. Most of the proteins identified in this study were abundant cytosolic proteins that were highly basic including in particular ribosomal proteins, proteins involved in DNA or RNA binding, and other abundant proteins, most of which have a high isoelectric point $>9$. Thus, examples of biomarker peaks assigned to proteins characterized by a high isoelectric point included not only ribosomal proteins but also many other proteins such as cold shock-like protein $\mathrm{CspH}$, translation initiation factor IF-1 (pI 9.23), DNA binding protein $\mathrm{HU} \alpha$ - and $\beta$ - (pI 9.69 and 9.57), the ribosome modulation factor (pI 10.56), and integration host factors A and B (both pI 9.34). Lower pI value proteins detected in this study were in general very abundant proteins including the nucleoid-associated protein $\mathrm{H}-\mathrm{NS}$ (pI 5.32), the RNA chaperone CspE (pI 8.08), glutaredoxin-1 (pI 5.63), and the phosphocarrier protein $\mathrm{HPr}$ (pI 5.6).

Thus, most of MALDI-TOF spectra are composed of very conserved proteins with house-keeping functions affected to a minimal extent by environmental conditions and thus considered to be optimal for routine identification of bacteria.

\section{Biomarkers reproducibility}

The reproducibility of MALDI-TOF spectrum of whole bacterial sample is problematic as large variations can be seen in spectra of the same bacterial species obtained in different conditions. Many experimental parameters can have an important effect on the observed mass spectra (Wang et al., 1998). The reproducibility is dependent on the MALDI-TOF instrument, the matrix used, the age of the microorganism, the sample : matrix ratio, the sample concentration, the culture medium and growth conditions (Valentine et al., 2005). However, several studies have shown that a subset of peaks from genetically identical bacteria was conserved in spectra obtained in different experimental conditions (Wang et al., 1998; Welham et al., 1998). These conserved peaks, among which ribosomal proteins are well represented, explain the feasibility to use MALDI-TOF for bacterial identification even without the standardization of experimental conditions. These results also suggest that selected specific conserved biomarker proteins could be used for bacterial identification irrespective of changes in other biomarkers. However, to optimize the reproducibility, a standardization of sample preparation (e.g. choice of matrix, concentrations, solvent and crystallization conditions) has to be established by diagnostic laboratories.

\section{Intra-laboratory reproducibility}

Only a few studies have reported investigations on intralaboratory reproducibility. In two studies that were focusing only on the presence or absence of particular peaks but not on peak intensities, the level or reproducibility obtained was equal to $75 \%$ or higher using the same mass spectrometer and similar sample preparation techniques (Saenz et al., 1999; Walker et al., 2002). The reproducibility of MALDI-TOF MS fingerprints was high even when mass spectra were obtained from bacterial cultures propagated in the same standard culture conditions during weeks and even months (Bernardo et al., 2002).

In our laboratory, we observed that the reproducibility is mainly dependent on the quality of the deposit and 
that the extraction step is not associated with significant supplementary variability. Thus, when considering the higher peaks ( $\geq 200$ intensity units) obtained with E. coli strain ATCC 25922 in 10 independent analyses, 66 peaks were present in all 10 replicates performed with proteins obtained from the same extraction whereas 78 peaks were present in the 10 spectra obtained from 10 independent extractions (Fig. 2a). Similar results were obtained with Staphylococcus aureus strain ATCC 25923 (Fig. 2b).
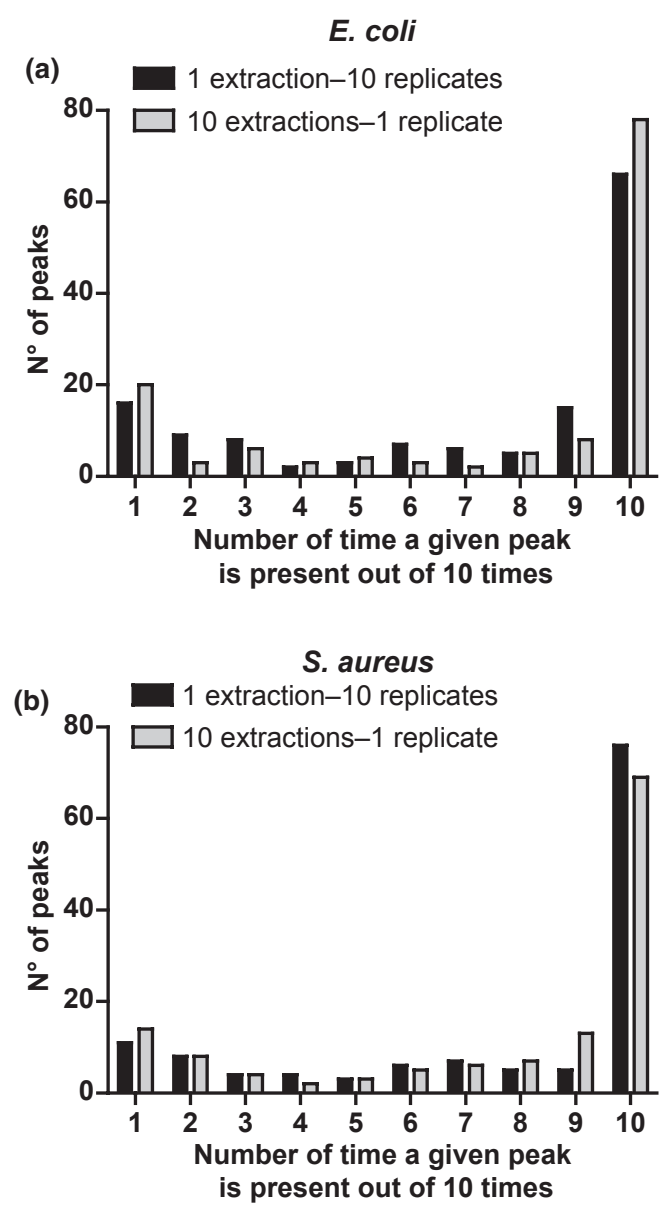

Fig. 2. Intra-laboratory reproducibility tested by measuring the number of conserved peaks in two experimental settings. In the first setting, ethanol/formic acid extraction was applied on Escherichia coli ATCC 25922 (a) or Staphylococcus aureus ATCC 25923 (b) and 10 replicates of one extraction were spotted onto the MALDI-TOF microplate $\left(1 \mu \mathrm{L}\right.$, about $10^{6}$ bacteria $\left.\mu \mathrm{L}^{-1}\right)$. In the second setting, 10 independent extractions were performed and one replicate of each extraction was spotted onto the MALDI-TOF microplate. After smoothing and baseline subtraction, the 100 highest peaks from each spot were selected and the number of time a given peak is present out of 10 times was determined for each peak in the two different settings for Escherichia coli and Staphylococcus aureus.

\section{Inter-laboratory reproducibility}

The variation of inter-laboratory reproducibility is not surprisingly much higher as small variation in sample preparation and analysis may significantly affect mass fingerprints. Unfortunately, only a few attempts have been made to compare results from different laboratories on the same organism (Mellmann et al., 2009). In addition, interlaboratory studies based on different comparative settings have been performed and gave very different results. Studies comparing mass spectra of identical microorganisms obtained in different locations but with the same experimental protocols and instruments hardware and software have shown promising results in terms of inter-laboratory reproducibility. For instance, two studies using different bacterial species have demonstrated that more than $60 \%$ of the peaks observed in mass spectra were similar in separate laboratories (Wang et al., 1998; Walker et al., 2002). However, a poor inter-laboratory reproducibility of MALDI-TOF MS of intact microorganisms was demonstrated in a study where three independent laboratories using three different commercial instruments performed a MALDI-TOF MS analysis of identical aliquots of E. coli culture prepared and analysed in the same experimental conditions (Wunschel et al., 2005). In this study, only $25 \%$ of the biomarkers were found in common by all three laboratories and more than $50 \%$ of the peaks were detected in spectra from only one of the three laboratory. Of importance, when the mass spectra collected from the instrument of one of the laboratory was analysed in the other two laboratories, $70 \%$ of the mass fingerprints could be identified correctly as E. coli. This finding underlines the importance of the instrument in the establishment of bacterial fingerprint databases.

\section{Application for microorganism identifications}

Two general MALDI-TOF MS methods have been proposed to characterize microorganisms: (1) mass spectra comparison with fingerprints database and (2) matching of biomarker masses to a proteome database (see Box S1). In the first approach, generated unique spectra of intact cells are compared with previously collected fingerprint libraries that are commercially available. This solution is rapid, simple, and is easily adaptable for routine use in diagnostic laboratories. This approach is convenient to develop specific databases constituted of unique and conserved peaks that can be used for species and subspecies identification, independently of the culture conditions used to grow the microorganism (Carbonnelle et al., 2007). In the second approach, the biomarker masses associated with an unknown microorganism are identified by matching protein molecular masses in the spectrum 
with protein molecular masses predicted from sequenced genomes (Demirev et al., 1999). This method is based on the observation that the majority of observed biomolecules above $4000 \mathrm{~m} / \mathrm{z}$ in MALDI-TOF spectra of whole cell extracts are proteins. An available algorithm predicts protein masses in silico from the genomes and seeks matches with experimentally derived masses (Pineda et al., 2000). However, this application is limited to microorganisms whose genomes are sequenced and further development in strategies for organization of the proteome database is required. The advantage of such a bioinformatics-based approach compared with bacterial fingerprinting is that the identification tolerates variations in the protein profiles and thus differences in culture growth and sample treatment conditions.

\section{Bacterial identification}

The identification of microorganisms in clinical diagnostic microbiology laboratories is nowadays mainly performed by analysis of biochemical reactions and phenotypic characteristics, such as growth on different media, colony morphology and Gram staining. When combined, these routine laboratory techniques ensure an accurate identification of most microorganisms but are costly, require time, and need in some cases well-trained technician for correct interpretation. One of the major advantages of using MALDI-TOF technology for bacterial identification is the time-to-result, which is reduced from 24 to $48 \mathrm{~h}$ to less than an hour. In addition, MALDI-TOF allowed accurate bacterial identification of a large variety of bacteria, that only exhibit few phenotypic traits and that were identified by $16 \mathrm{~S}$ rRNA gene sequencing prior to the MALDI-TOF era (Bizzini et al., 2011).

\section{Routine identification}

Several approaches are commonly used in routine diagnostic laboratories. One typical approach is to pick bacterial isolates colonies freshly grown on defined agar medium with a sterile tip and to smear a thin film onto a ground steel MALDI target plate. The microbial film is then overlaid with a MALDI matrix selected as recommended by the MALDI-TOF manufacturers, typically $1.5 \mu \mathrm{L}$ CHCA in $50 \%$ acetonitrile/2.5\% trifluoroacetic acid for the Bruker instrument and $0.5 \mu \mathrm{L}$ of $20 \mathrm{mg}$ DHB dissolved in $1 \mathrm{~mL}$ water-ethanol-acetonitrile $[1: 1: 1]$ mix for the Shimadzu instrument. In our laboratory, to increase identification yield, we routinely add formic acid on smeared microorganisms before adding the matrix. The sample-matrix mixture is dried at room temperature and then introduced in the MALDI-TOF instrument for data acquisition. The data are processed by the associated softwares (see above) and the spectra are compared with reference libraries for bacterial identification. A protein extraction step using ethanol-acetonitrile is performed when direct application procedure failed.

Several studies have analysed the bacterial identification efficiency of these two instruments (Bruker and Shima$\mathrm{dzu}$ ) with their respective software and databases (Table 1). We will present here the results of (1) two intra-laboratory studies using the Bruker system (Seng et al., 2009; van Veen et al., 2010), (2) an intra-laboratory study evaluating the two instruments using the same microbial samples (Cherkaoui et al., 2010), and (3) a large international interlaboratory study performed with the Bruker instrument (Mellmann et al., 2009).

Using the Bruker system, 327 clinical isolates previously identified by conventional techniques were analysed using MALDI-TOF MS by van Veen et al. (2010). The authors observed a $95.1 \%$ correct identification at the genus level and a $85.6 \%$ at the species level. The same group performed a prospective validation study on 980 clinical isolates of bacteria and yeast that showed a $92.2 \%$ correct identification by MALDI-TOF, a performance significantly better than the $83.1 \%$ identification obtained with conventional biochemical systems. Correct species identification by MADLI-TOF MS was observed in $97.7 \%$ of Enterobacteriaceae, $92 \%$ of nonfermentative Gram-negative bacteria, $94.3 \%$ of staphylococci, $84.8 \%$ of streptococci, $84 \%$ of bacteria of the HACCEK group (Haemophilus, Actinobacillus, Cardiobacterium, Capnocytophaga, Eikenella, and Kingella) and $85.2 \%$ of yeasts. In this work, misidentification was clearly associated with insufficient spectra from suitable reference strains in the reference spectra database.

Seng et al. (2009) have conducted a prospective routine MALDI-TOF MS identification analysis with the Bruker system on 1660 bacterial isolates in parallel with conventional phenotypic bacterial identification. Discrepancies were resolved by $16 \mathrm{~S}$ rRNA and $r p o B$ gene sequencing. They have shown that $95.4 \%$ of the isolates were correctly identified using MALDI-TOF MS among which $84.1 \%$ at the species level and $11.3 \%$ at the genus level only. Absence of identification (2.8\% of isolates) and incorrect identification $(1.7 \%$ of isolates) were mainly due to improper database entries. They have estimated that the MALDI-TOF identification required an average time of 6 min for an estimated $70-80 \%$ reduced cost compared with conventional methods of identification.

Cherkaoui et al. (2010) have evaluated the two main MALDI-TOF MS systems, Bruker and Shimatzu, in a comparative study with 720 bacterial isolates under routine clinical laboratory conditions. The isolates were 
Table 1. Performance of routine identification by MALDI-TOF MS

\begin{tabular}{|c|c|c|c|c|c|c|c|}
\hline References & $N$ & Description & $\begin{array}{l}\text { Genus level } \\
(\%)\end{array}$ & $\begin{array}{l}\text { Species } \\
\text { level (\%) }\end{array}$ & $\begin{array}{l}\text { Mis- } \\
\text { identification } \\
(\%)\end{array}$ & No ID (\%) & Comments \\
\hline \multirow{6}{*}{$\begin{array}{l}\text { van Veen } \\
\text { et al. } \\
(2010)\end{array}$} & 327 & Total & 95.1 & 85.6 & 3 & 3.9 & \multirow{6}{*}{$\begin{array}{l}\text { Retrospective intra-laboratory } \\
\text { study } \\
\text { Misidentification: associated } \\
\text { with absence or mislabeling } \\
\text { of reference spectra in } \\
\text { the database }\end{array}$} \\
\hline & 89 & Enterobacteriaceae & 100 & 96.6 & 3.4 & 0 & \\
\hline & 55 & Non-fermentative GN & 81.8 & 74.5 & 5.4 & 14.5 & \\
\hline & 87 & GP cocci & 97.7 & 80.5 & 1.1 & 2.3 & \\
\hline & 77 & $\begin{array}{l}\text { Miscellaneous bacteria } \\
\text { (HACCEK) }\end{array}$ & 94.8 & 84.4 & 3.9 & 1.3 & \\
\hline & 19 & Yeasts & 100 & 94.7 & 0 & 0 & \\
\hline \multirow{12}{*}{$\begin{array}{l}\text { van Veen } \\
\text { et al. } \\
(2010)\end{array}$} & 980 & Total & 98.8 & 92 & 1.7 & 1.1 & \multirow{12}{*}{$\begin{array}{l}\text { Prospective intra-laboratory } \\
\text { study } \\
\text { Misidentification: associated } \\
\text { with absence or mislabeling } \\
\text { of reference spectra in } \\
\text { the database } \\
\text { Viridans streptococci and } \\
\text { pneumococci characterized } \\
\text { by many misidentifications } \\
\text { Weakness of the study: } \\
\text { lack of sufficient } \\
\text { anaerobic bacteria and } \\
\text { GP aerobic rods included } \\
\text { in the tested samples }\end{array}$} \\
\hline & 311 & Enterobacteriaceae & 100 & 97.7 & 0.3 & 0 & \\
\hline & 88 & Non-fermentative GN & 94.3 & 92 & 1.1 & 4.6 & \\
\hline & 261 & GP cocci in cluster & 100 & 94.3 & 0.4 & 0 & \\
\hline & \multirow[t]{6}{*}{165} & GP cocci in chains & 98.8 & 84.8 & 7.3 & 1.2 & \\
\hline & & Enterococci & 100 & 98.4 & 0 & 0 & \\
\hline & & $\begin{array}{l}\text { Hemolytic } \\
\text { streptococci }\end{array}$ & 100 & 100 & 0 & 0 & \\
\hline & & $\begin{array}{l}\text { Streptococcus } \\
\text { milleri group }\end{array}$ & 100 & 77.8 & 0 & 0 & \\
\hline & & Pneumococci & 100 & 86.4 & 0 & 0 & \\
\hline & & $\begin{array}{l}\text { Viridans } \\
\text { streptococci }\end{array}$ & 90.5 & 9.5 & 57.1 & 9.5 & \\
\hline & 94 & $\begin{array}{l}\text { Miscellaneous bacteria } \\
\text { (HACCEK) }\end{array}$ & 96.8 & 84 & 0 & 3.2 & \\
\hline & 61 & Yeasts & 96.7 & 85.2 & 3.3 & 3.2 & \\
\hline \multirow{3}{*}{$\begin{array}{l}\text { Seng et al. } \\
(2009)\end{array}$} & 1660 & Total & 95.4 & 84.1 & 1.7 & 2.8 & \multirow{3}{*}{$\begin{array}{l}\text { Prospective intra-laboratory } \\
\text { study } \\
\text { Lack of identification mainly } \\
\text { for non-Clostridium } \\
\text { anaerobes due to an } \\
\text { absence of reference spectra } \\
\text { in the database }\end{array}$} \\
\hline & ND & GP & & & 0.8 & 2 & \\
\hline & ND & GN & & & 0.9 & 0.7 & \\
\hline \multirow{7}{*}{$\begin{array}{l}\text { Cherkaoui } \\
\text { et al. } \\
(2010)\end{array}$} & 720 & Total & \multirow[t]{7}{*}{100} & $94 * / 89^{\dagger}$ & $0.9 * / 0.5^{\dagger}$ & & \multirow{7}{*}{$\begin{array}{l}\text { Comparative intra-laboratory } \\
\text { study of two commercial } \\
\text { MALDI-TOF MS devices } \\
\text { (Bruker and Shimatzu) } \\
\text { Poor yield for streptococcal } \\
\text { species and for GN } \\
\text { anaerobes (<50\% correct } \\
\text { identification) }\end{array}$} \\
\hline & 416 & Enterobacteriaceae & & $99.8^{*} / 95.9^{\dagger}$ & $0 * / 0^{\dagger}$ & & \\
\hline & 80 & Aerobic GN & & $97.5^{*} / 96.3^{\dagger}$ & $1.25 * / 0^{\dagger}$ & & \\
\hline & 111 & Staphylococci & & $98.2 * / 96.4^{\dagger}$ & $0.9 * / 0.9^{\dagger}$ & & \\
\hline & 87 & Aerobic GP & & $73.6^{*} / 55.2^{\dagger}$ & $3.4^{*} / 2.3^{\dagger}$ & & \\
\hline & 6 & Anaerobic GN & & $17 * / 0^{\dagger}$ & $0 * / 0^{\dagger}$ & & \\
\hline & 7 & Anaerobic GP & & $57 * / 43^{\dagger}$ & $25 * / 0^{\dagger}$ & & \\
\hline \multirow{9}{*}{$\begin{array}{l}\text { Mellmann } \\
\text { et al. } \\
(2009)\end{array}$} & 480 & Total & & 98.7 & 1.04 & 0.2 & \multirow{9}{*}{$\begin{array}{l}\text { Interlaboratory study } \\
60 \text { non-fermenting bacteria } \\
\text { were shipped to } 8 \text { different } \\
\text { laboratories with access to } \\
\text { Bruker platforms } \\
\text { No significant difference } \\
\text { between direct application } \\
\text { and preprocessed samples } \\
\text { Misidentification: } \\
\text { sample interchange (4) } \\
\text { and skin contamination (1) }\end{array}$} \\
\hline & 60 & Laboratory A & & 100 & 0 & 0 & \\
\hline & 60 & Laboratory B & & 96.67 & 1.7 & 1.7 & \\
\hline & 60 & Laboratory C & & 100 & 0 & 0 & \\
\hline & 60 & Laboratory D & & 93.33 & 6.66 & 0 & \\
\hline & 60 & Laboratory E & & 100 & 0 & 0 & \\
\hline & 60 & Laboratory F & & 100 & 0 & 0 & \\
\hline & 60 & Laboratory G & & 100 & 0 & 0 & \\
\hline & 60 & Laboratory H & & 100 & 0 & 0 & \\
\hline
\end{tabular}


Table 1. Continued.

\begin{tabular}{|c|c|c|c|c|c|c|c|}
\hline References & $N$ & Description & $\begin{array}{l}\text { Genus level } \\
(\%)\end{array}$ & $\begin{array}{l}\text { Species } \\
\text { level (\%) }\end{array}$ & $\begin{array}{l}\text { Mis- } \\
\text { identification } \\
(\%)\end{array}$ & No ID (\%) & Comments \\
\hline \multirow{8}{*}{$\begin{array}{l}\text { Bizzini } \\
\text { et al. } \\
(2010)\end{array}$} & 1371 & Total direct application & & 70.3 & & & \multirow{12}{*}{$\begin{array}{l}\text { Intra-laboratory study } \\
\text { Protein extraction increases } \\
\text { the total yield of valid } \\
\text { results by } 25 \% \text { compared } \\
\text { with direct application } \\
\text { Misidentification: inaccurate } \\
\text { taxonomic assignment, } \\
\text { change in the taxonomy, } \\
\text { limit of resolution of the } \\
\text { method } \\
\text { Intra-laboratory study of } \\
\text { clinical yeast isolates } \\
\text { [Candida ( } n=250 \text { ), } \\
\text { Cryptococcus, } \\
\text { Saccharomyces, } \\
\text { Trichosporon, Geotrichum, } \\
\text { Pichia and } \\
\text { Blastoschizomyces spp.] } \\
\text { All isolates identified upon } \\
\text { complementation of the } \\
\text { database with appropriate } \\
\text { reference strains } \\
\text { All samples were } \\
\text { preprocessed with a protein } \\
\text { extraction step before } \\
\text { deposition } \\
\text { Comparative intra-laboratory } \\
\text { study of two commercial } \\
\text { MALDI-TOF MS devices } \\
\text { (Bruker and Shimatzu) on } \\
\text { clinical yeast isolates } \\
\text { Better yield observed when } \\
\text { the performance is only } \\
\text { tested on species present } \\
\text { in respective databases } \\
\text { All sample were } \\
\text { preprocessed with a protein } \\
\text { extraction step before } \\
\text { deposition }\end{array}$} \\
\hline & 1371 & Total protein extraction & 95.4 & 92.6 & 4.2 & 4.6 & \\
\hline & 525 & GP direct application & & 73.7 & & & \\
\hline & 525 & GP protein extraction & 99.6 & 98.85 & 0.95 & 0.4 & \\
\hline & 729 & GN direct application & & 71.6 & & & \\
\hline & 729 & GN protein extraction & 97 & 92.2 & 7 & 3 & \\
\hline & 24 & Yeasts direct application & & 4.1 & & & \\
\hline & 24 & $\begin{array}{l}\text { Yeasts protein } \\
\text { extraction }\end{array}$ & 100 & 100 & 0 & 0 & \\
\hline \multirow[t]{2}{*}{$\begin{array}{l}\text { Marklein } \\
\text { et al. } \\
\text { (2009) }\end{array}$} & 267 & $\begin{array}{l}\text { Total before } \\
\text { complementation } \\
\text { of database }\end{array}$ & & 92.5 & & 7.5 & \\
\hline & 267 & $\begin{array}{l}\text { Total after } \\
\text { complementation } \\
\text { of the database }\end{array}$ & & 100 & & 0 & \\
\hline Bader & 1192 & Total & & $97.6 * / 96.1^{\dagger}$ & $0.7 * / 0.2^{\dagger}$ & $1.7 * / 3.7^{\dagger}$ & \\
\hline $\begin{array}{l}\text { et al. } \\
\text { (2010) }\end{array}$ & $1175^{*} / 1152^{\dagger}$ & $\begin{array}{l}\text { Challenged } \\
\text { against } \\
\text { respective database }\end{array}$ & & $99 * / 99.4^{\dagger}$ & $0.5 * / 0^{\dagger}$ & $0.5 * / 0.6^{\dagger}$ & \\
\hline
\end{tabular}

Genus and species level (\%), percent of identification at the genus and species level respectively. Misidentification (\%), percent of misidentified samples. No ID (\%), percent of samples not identified. *Bruker system, `Shimatzu.

$N$, sample number; GP, Gram-positive; GN, Gram-negative.

analysed in parallel on both devices according to the manufacturers' default recommendations. The MALDITOF MS results were compared with conventional biochemical identification tests and discordant results were resolved with 16S rRNA gene sequencing. The Bruker MS system gave high-confidence identification for 680 of 720 isolates (94.4\%) whereas the Shimadzu MS showed a high-confidence identification for 639 isolates (88.8\%). These results showed also that only $6 / 680(0.9 \%)$ of the
Bruker and 3/639 (0.5\%) of the Shimadzu identifications gave an incorrect high-confidence identification at the species level. All the high-confidence MS identifications were accurate at the genus level. In addition, the Bruker MS system has identified 9 (69\%) and the Shimadzu system $5(38 \%)$ of 13 isolates that were not identified by conventional phenotyping methods.

Interlaboratory species identification was assessed in a large international multicenter study (Mellmann et al., 
2009) using the Bruker system. In this study, eight participating laboratories received 60 blind-coded samples for MALDI-TOF MS species identification and $98.75 \%$ were correctly identified at the species level. Six of the eight laboratories identified all 60 samples correctly. Out of a total of 480 samples, six samples were misidentified and one sample did not give any valid result due to low signal intensity. Thus, in contrast to other studies (Wang et al., 1998), the utilization of a commercial system developed for routine use provided high reliability for bacterial identification.

Although excellent results have been shown for bacterial identification by MALDI-TOF MS, both the diagnostic yield (identification at the genus, species or strain level) and the accuracy of identification depends on the taxonomy and in the quality of the databases. As shown by many studies, most of the bacterial groups including Enterobacteriaceae, nonfermentative Gram-negative bacteria, staphylococci, and hemolytic streptococci were correctly identified as the species level (Seng et al., 2009; Cherkaoui et al., 2010; van Veen et al., 2010). Regarding staphylococci, the MALDI-TOF MS has brought up an important advantage by allowing rapid and simplified identification of both $S$. aureus and of some species belonging to coagulase-negative staphylococci (CoNS). Unlike most commercial identification systems that allow a rapid identification of only $S$. aureus, the MALDI-TOF MS allows a correct identification of various CoNS species (Speers et al., 1998; Bernardo et al., 2002; Dupont et al., 2010). In a comparative study between MALDITOF MS and two rapid identification automated systems, BD Phoenix (BD Diagnostic Systems, France) and Vitek-2 (bioMérieux, Marcy l'Etoile, France), the identification of 234 CoNS belonging to 20 different species showed that the MALDI-TOF performance was significantly better (93.2\%) than Phoenix (75.6\%) and Vitek-2 performance (75.2\%) (Dupont et al., 2010). Overall, MALDI-TOF appears to be excellent at identifying various staphylococci species as demonstrated by the congruence of $99.3 \%$ (444/ 447) between MALDI-TOF and $r p o B$ sequence-based identifications (Spanu et al., 2011). As CoNS can cause serious infections and are frequently associated with hospital-acquired infections, the rapid identification at the species level by MALDI-TOF is very useful in distinguishing clinically significant CoNS from contaminant strains (von Eiff et al., 2002).

\section{Problematic identifications}

Most of the problematic identifications encountered in most of the recent studies concerned the viridans streptococci group, the pneumococci and anaerobic bacteria (Table 2). Viridans streptococci and pneumococci were commonly misidentified mainly due to an incomplete database reference library. In the study by Seng et al. (2009), nearly 50\% of Streptococcus pneumoniae isolates were misidentified as Streptococcus parasanguinis [a close

Table 2. Problems commonly found in routine identification by MALDI-TOF MS

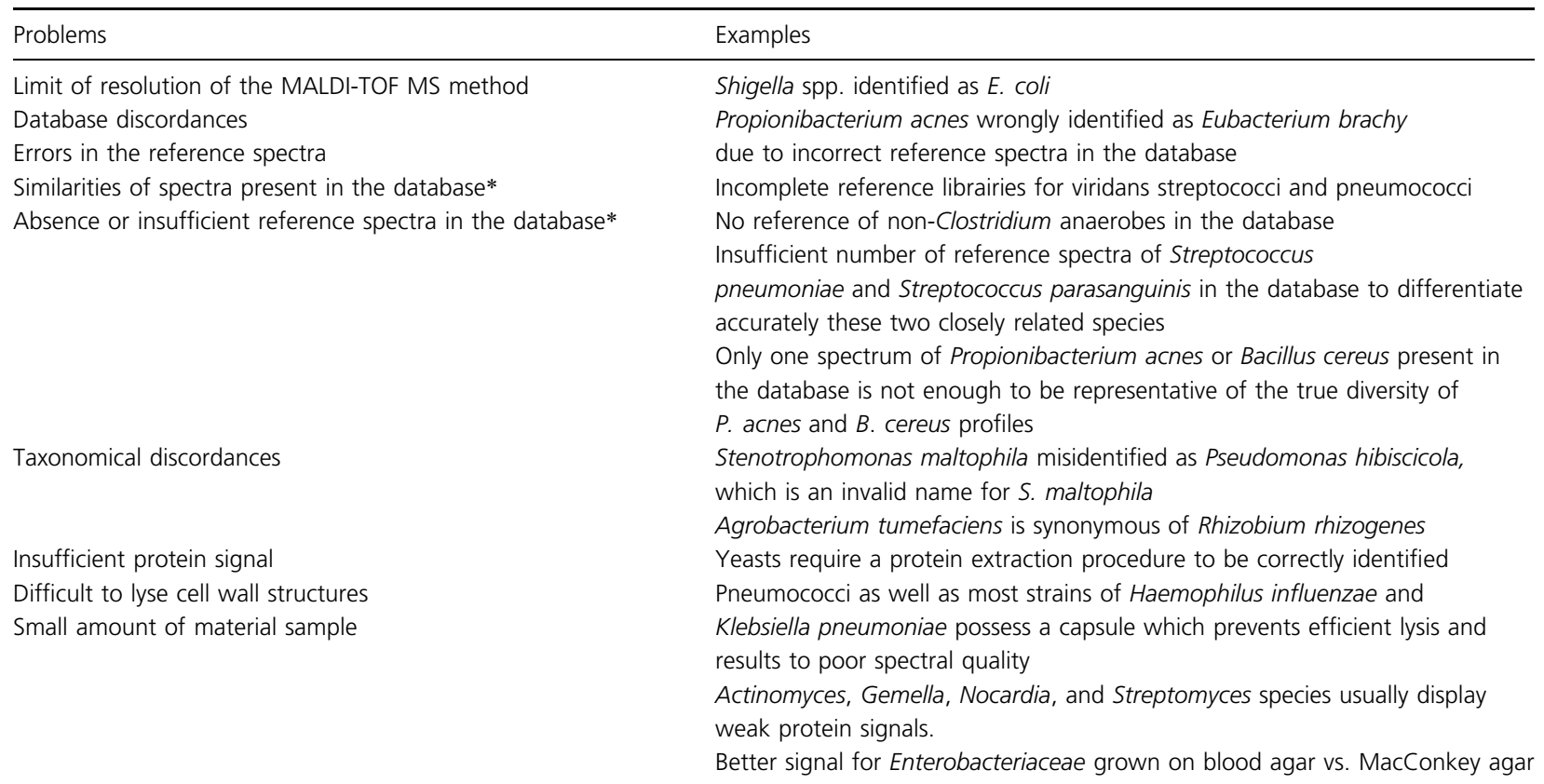

*A higher number of reference spectra in the database are usually required to accurately identify closely related microorganisms that display a high degree of spectrum similarities. Thus, these two parameters are interdependent. 
related species within the mitis group of Streptococcus species (Kawamura et al., 1995)] because the database contained only three S. pneumoniae and two S. parasanguinis reference spectra. The problem was solved by adding additional S. pneumoniae isolates reference spectra to the database which clearly indicates that the database need to be updated with multiple spectra of well-characterized streptococcal species. Until now, the identification of Streptococcus spp. remains a problem for MALDI-TOF MS identification especially for closely related species such as S. pneumoniae, Streptococcus mitis, and S. parasanguinis. In the case of pneumococci, the use of MALDITOF MS for identification is further impaired by the weak extraction yield caused by the presence of a capsule. Thus, identification of S. pneumoniae should not solely rely on MALDI-TOF as false identification can results in important clinical outcomes. In the study by Cherkaoui et al. (2010), the diagnostic yield for streptococcal species and for Gram-negative anaerobes was $<50 \%$ with an accuracy of high-confidence species identification of only $57.1 \%$ for streptococci with the Bruker system and of $71.4 \%$ with the Shimadzu MS system.

To date, only a few studies have analysed the usefulness of MALDI-TOF for routine identification of anaerobic bacteria. Seng et al. (2009) showed that an improved database is required as $50 \%$ of the total isolates (46) showing no identification by MALDI-TOF MS were anaerobic bacteria including Fusobacterium nucleatum and non-Clostridium anaerobes that had no reference in the Bruker database. In contrast, for anaerobic species (e.g. several Bacteroides species) with sufficient spectra in the database, the identification by MALDI-TOF MS was better compared with that by conventional biochemical methods. These fastidious organisms are poorly identified using phenotypic methods with a lack of specificity and ambiguous or false identification. There is thus an important need to improve the database entries with additional anaerobes isolates (Bessede et al., 2011).

Similar to other studies, Blondiaux et al. (2010) have demonstrated the difficulties to identify viridans streptococci, pneumococci as well as HACCEK bacteria but also Shigella and several strictly aerobic bacteria (Aeromonas spp., Achromobacter spp., Alcaligenes spp.). In this study, the mass spectra of six Shigella isolates were similar to several E. coli strains present in the Biotyper database. In another study, the misidentification of all Shigella sonnei isolates with E. coli was also documented (Seng et al., 2009).

Using 43 selected Mycobacteria strains, a mycobacterial database could be engineered comprising species-specific spectral profiles allowing identification of 44 species at the species level and of nine strains of the Mycobacterium abscessus complex and the Mycobacterium tuberculosis complex at the mycobacterial clade level (Lotz et al., 2010). Under the preanalytical and analytical conditions used in this study, subspecies of the Mycobacterium abscessus complex (Mycobacterium abscessus, Mycobacterium massiliense and Mycobacterium bolletti) and the Mycobacterium tuberculosis complex (Mycobacterium tuberculosis, Mycobacterium bovis, Mycobacterium microti and Mycobacterium africanum) produced indistinguishable mass profiles due to their high degree of genetic similarity. Using this microbial database, 311 strains grown on solid medium were analysed using MALDI-TOF MS allowing a 97\% correct identification, $67 \%$ at the species level and $30 \%$ at the complex level, respectively. No misidentification was observed. When bacteria were grown on liquid media, correct identification was reduced to $77 \%$, likely due to a reduced number of bacterial load or to potential interference with components of the liquid media. Interestingly, the authors observed that an increase in number of replicates (up to 5) did correlate with an increase in the probability of good identification, especially for slow-growing mycobacteria. Overall, several studies demonstrate that MALDI-TOF MS provides high reproducibility and specificity for mycobacterial identification and represents an alternative to other time consuming and fastidious conventional mycobacterial identification methods (Hettick et al., 2004; Lefmann et al., 2004; Pignone et al., 2006; Lotz et al., 2010).

In our study analysing the performance of MALDITOF MS for the identification of 1371 bacterial isolates routinely isolated in clinical microbiology laboratories and characterized by conventional methods, 1278 (93.2\%) bacterial isolates were identified at the species level, 73 $(5.3 \%)$ were only identified at the genus level and 20 $(1.5 \%)$ gave no reliable identification (Bizzini et al., 2010). Among the 1278 isolates identified at the species level, $63(4.9 \%)$ were misidentified. The majority of discordant results (42/63) were explained by discordances due to the MALDI-TOF database, 14 were due to poor discrimination of the spectra of closely related species such as Shigella spp. and E. coli, and seven were caused by errors in the initial conventional phenotypic and biochemical identifications.

Many of the bacterial identifications that can be peformed only at the genus level are due to incomplete reference spectra covering many different isolates or species from a given genus. For instance, only one reference spectrum of Propionibacterium acnes (strain DSM 1897) or Bacillus cereus are included in the Bruker database which is totally insufficient to cover the true diversity of these bacteria and thus to identify accurately these microorganisms (Bizzini et al., 2010). In addition, mislabelling of bacterial species in the database can cause misidentification by MALDI-TOF MS. In the study by Seng et al. (2009), seven Stenotrophomonas maltophilia isolates 
were incorrectly identified as Pseudomonas hibiscicola which is an invalid name for a nonfermenting Gram-negative rod that was demonstrated to be S. maltophilia.

These studies show that a complete and representative database is an essential requirement for accurate identification of isolates by MALDI-TOF MS. A frequent update of the reference library database with spectra of appropriate poorly represented reference strains by the manufacturers but also by routine diagnostic laboratories can significantly impact the MALDI-TOF identification performance.

\section{Impact of sample preparation on MS identification}

Sample preparation has not been shown to be a major issue for problematic identifications. Samples and matrix prepared according to manufacturer's instructions usually guarantee high quality spectral fingerprints required for efficient MALDI-TOF identifications. In most cases, the composition of an appropriate matrix containing strong solvent ensures efficient bacterial lysis required for MALDI-TOF analysis. When invalid results are initially obtained by MALDI-TOF MS following analysis of intact bacteria directly deposited on MALDI target plate, a step of bacterial protein extraction with acid-containing sample solvents improving cell lysis solves the problem in most cases. Bizzini et al. (2010) have shown that a formic acid-acetonitrile extraction step was required to get a valid MALDI-TOF MS identification for $25.6 \%$ of the 1278 valid isolates. The yield of valid score from direct application was almost the same, about $75 \%$, for both Gram-positive and Gram-negative bacteria. For instance, the yields of valid scores without extraction step were equal to $79 \%$ for $S$. aureus, $82 \%$ for Enterococcus faecalis, $92 \%$ for P. aeruginosa, $74 \%$ for E. coli, $58 \%$ for Klebsiella pneumoniae and 58\% for Staphylococcus epidermidis. However, the authors concluded that protein extraction prior to MALDI-TOF analysis should be performed only in particular cases known to be problematic such as colonies isolated from urine culture devices and/or MacConkey agar which contains crystal violet, a possible interfering substance affecting mass peak signals. Indeed, the higher identification rate obtained after an extraction step largely compensates the longer hand-on-time associated with an extraction procedure.

This was also demonstrated in a study performed by Liu et al. (2007) who have developed a universal sample preparation for characterization of bacteria by MALDI-TOF MS. The protocol, consisting of a pretreatment of bacteria with acidic sample solvents and mixing with CHCA or 5-chloro-2-mercaptobenzothiazole (CMBT) matrix, could be used to analyse both Gram-positive bacteria, including spore-producing $B$. anthracis and non-spore-producing
S. aureus, and Gram-negative bacteria such as Yersinia pestis, E. coli, and Burkholderia cepacia that are characterized by high extracellular-polysaccharide contents.

However, for some microorganisms, insufficient cell lysis and/or low quantity of sample material can be problematic for efficient MALDI-TOF identification and require the use of alternative identification approaches such as 16S rRNA gene sequencing. A study by Bizzini et al. (2011) focusing on the identification of 410 clinical isolates that could not be identified with conventional laboratory methods showed that $133 / 410(32.4 \%)$ isolates could not be either reliably identified with MALDI-TOF. The failure to obtain a reliable identification was due to the absence of reference spectra in the BioTyper database for $58 \%(78 / 133)$ of the isolates and to poor protein spectral signals for $41.4 \%(55 / 133)$ of the isolates. The authors supposed that the poor spectrum quality observed could be due to either the difficulty to lyse the cell wall of some bacteria such as Gram-positive bacilli and/or to fastidious growth of some isolate, which yielded only small amount of available sample material. Difficult to identify microorganisms belonging to the genera Actinomyces, Gemella, Nocardia, and Streptomyces could be observed in this study.

The rate of successful identification is directly linked to the amount of microorganism available. We have observed that the rate of correct identification is especially poor when the subculture has been incubated on a plate for $<4 \mathrm{~h}$ (Fig. 3). Thus, when we tried to identify various bacterial species isolated from positive blood cultures and sub-cultured on agar, we observed that only $30 \%$ of bacteria could be successfully identified after $2 \mathrm{~h}$ of incubation (Fig. 3c). This identification rate was significantly lower for Gram-positive cocci, remaining below $60 \%$ after $6 \mathrm{~h}$. This is likely due to the amount of bacteria available after short incubation period (Fig. 3b). Indeed, using 10-fold dilutions of E. coli strain ATCC 25922 and S. aureus strain ATCC 25923, we could show that as many as $10^{6}$ bacteria per well were necessary to consistently obtain a spectrum (Fig. 3a) ensuring a score above 2 and that when the amount of bacteria was ranging between $10^{2}$ to $10^{4}$ bacteria per well, the score was always below 1.7 (data not shown). A lower amount of bacteria may, however, be identified using a different identification algorithm. Hsieh et al. (2008) have demonstrated that as few as $5 \times 10^{3}$ cells from a pure strain can be identified by MALDI-TOF MS using particular analysis approaches based on selected markers (Hierarchical Clustering Analysis and direct classification model construction). Interestingly, using the classification model analysis, the authors showed that successful MALDI-TOF MS identification can also be achieved from a bacterial species mixture consisting of as few as $3 \times 10^{4}$ cells. This 


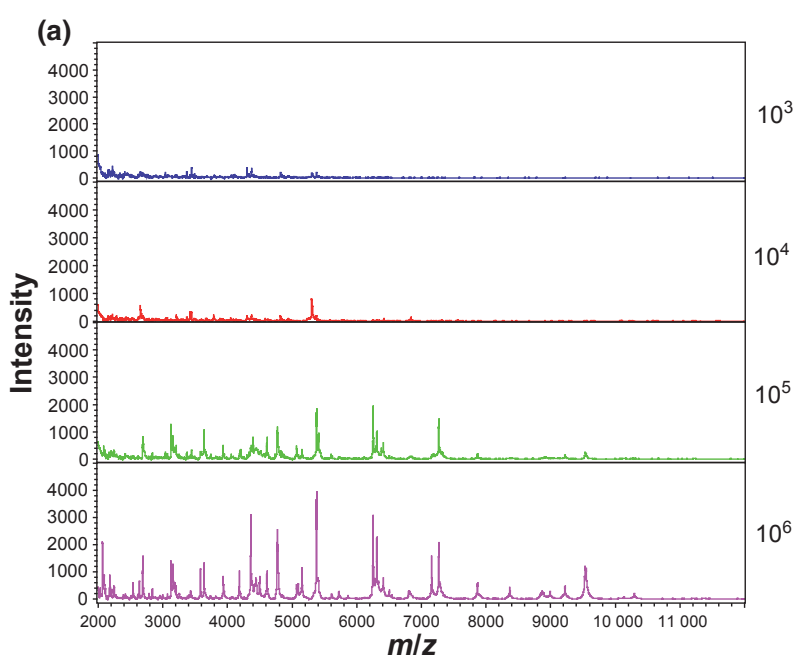

(b)

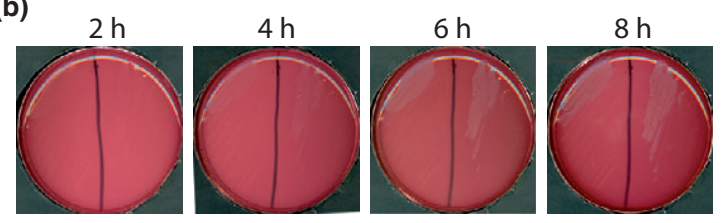

(c)

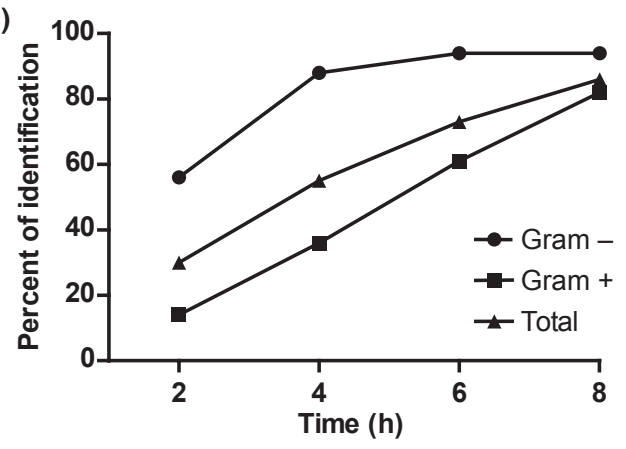

Fig. 3. The amount of material is a critical factor for accurate microbial identification by MALDI-TOF MS. (a) Spectral fingerprints obtained from various quantities $\left(10^{6}-10^{3}\right)$ of Escherichia coli ATCC 25922 grown on blood agar plates. The inoculums were prepared from a sample with a turbidity of $4.0 \mathrm{McF}$ arland that was diluted to obtain the approximate quantity used for direct microplate deposition $\left(10^{6}-10^{3}\right.$ bacteria per spot). Protein extraction was performed by directly mixing the samples with formic acid on microplate. The results show that the quality of the spectrum and thus the performance of identification are largely dependent on the sample amount spotted on the microplate. (b) Growth of Staphylococcus epidermidis on blood agar plates at $35{ }^{\circ} \mathrm{C}$ in $5 \% \mathrm{CO}_{2}$ atmosphere after an incubation of 2 , 4,6 , and $8 \mathrm{~h}$, respectively. Usually, at least $6 \mathrm{~h}$ of incubation are required to get sufficient amount of material to obtain an efficient MALDI-TOF MS identification (c) Cumulative percentage of MALDI-TOF identification obtained from Gram-negative [Escherichia coli (13), Pseudomonas putida (2), Klebsiella pneumoniae (2), Enterobacter cloacae (1)] and Gram-positive [Staphylococcus epidermidis (13), Staphylococcus aureus (9), Streptococcus pyogenes (4), Streptococcus pneumoniae (1), Staphylococcus hominis (1)] bacteria after short-time plating on agar during $2,4,6$, and $8 \mathrm{~h}$, respectively. The number of samples for each bacterial species analysed is indicated in brackets. study opens new perspectives for the direct identification of low abundant bacteria located in mixed flora without the prerequirement of bacterial isolation and culturing.

\section{Fungal identification}

Fungal identification still largely relies on phenotypic traits. However, a few days are necessary to obtain mature fungi with phyalids (phyalids are conidiogenous cells observed in a type of fungal asexual reproduction leading to the production of conidia). This time delay may be important given the morbidity and mortality of fungal infections, especially common and life threatening among neutropenic patients. Thus, like PCR and sequencing, MALDI-TOF has the potential to provide accurate and objective identification at species level, with the additional advantage of rapidity and reduced costs compared with PCR and sequencing.

MALDI-TOF MS systems for the identification of microorganisms were successfully adapted for the identification of fungi in the past 10 years. In 2000, Welham et al. were among the first to perform fungal identification using the MALDI-TOF MS approach (Welham et al., 2000). Three fungal species, Penicillium spp., Scytalidium dimidiatum, and Trychophyton rubrum, showed distinct spectral fingerprints allowing accurate species distinction. Since then, many studies have demonstrated the usefulness of the MALDI-TOF application for the identification of various fungal groups such as penicillia, aspergilla, Fusarium, Trichoderma, and dermatophytes. However, until now, MALDI-TOF MS is mainly used for the routine identification of yeasts whereas further development has to be accomplished in database libraries and sample preparation protocols to implement this identification approach to other group a of fungi such as filamentous fungi and dermatophytes.

\section{Yeasts}

The databases of the associated softwares (Biotyper and Saramis of the two main MALDI-TOF instruments contains reference spectra of multiple clinical yeast isolates, including several Candida spp. and Cryptococcus neoformans, which allows the use of MALDI-TOF in routine yeast laboratory identification (Table 1).

Marklein et al. (2009) evaluated MALDI-TOF MS for the rapid routine identification of clinical yeast isolates and showed that $92.5 \%(247 / 267)$ of clinical isolates of Candida, Cryptococcus, Saccharomyces, Trichosporon, Geotrichum, Pichia, and Blastoschizomyces spp. were accurately identified. In a study performed by van Veen $e t$ al. (2010), 85\% of 61 yeast isolates comprising 12 different species were correctly identified without occurrence of 
major errors. Bizzini et al. (2010) achieved a $100 \%$ correct identification of 24 yeast isolates belonging to 12 different species. The suitability of the two commercially available MALDI-TOF MS systems, Bruker and Shima$\mathrm{dzu}$, and their respective associated softwares and databases, Biotyper and Saramis, was tested for rapid species identification of yeasts in a clinical diagnostic approach (Bader et al., 2010). Both MALDI-TOF MS systems have showed a similar species identification rate of $97.6 \%$ for Bruker/Biotyper and $96.1 \%$ for Shimadzu/Saramis that were comparable with the biochemical tests rate $(96.9 \%)$. Based on isolates that were contained in the respective database, no misclassifications were seen with Saramis and fewer misidentifications were reported by the Biotyper compared with classical approaches. Using the Bruker MALDI-TOF system, Stevenson et al. (2010b) have created a spectral database library for 109 reference strains of yeast representing 44 species and eight genera to evaluate the use of MALDI-TOF MS for the rapid identification of yeast species. This library was challenged with 197 clinical isolates. Three isolates gave no spectral score as no reference spectrum were included in the database library. Of the remaining 194 clinical isolates, 192 (99.0\%) were correctly identified at the species level and two organisms gave consistently low spectral scores that could not be identified. In summary, the use of MALDI-TOF MS for the identification of clinically relevant yeasts is rapid and accurate providing that the database is constructed with a comprehensive collection of accurately identified reference strains.

\section{Filamentous fungi}

Chen \& Chen (2005) successfully identified several Penicillium species directly from intact fungal spores mixed with the MALDI matrix. Hettick et al. (2008b) have achieved 100\% correct identifications of 12 Penicillium species by bead beating fungal samples resuspended in a acetonitrile/trifluoroacetic acid solvent prior to MALDITOF analysis. The observed mass spectra contained abundant peaks in the range 5000-20 $000 \mathrm{~m} / \mathrm{z}$ allowing unambiguous discrimination between species. In addition, a biomarker common to all Penicillium mass fingerprints was observed at $m / z$ of $13.9 \mathrm{kDa}$.

Using an extraction method similar to that used for Penicillium species, Hettick et al. (2008a,b) obtained also highly reproducible mass spectral fingerprints for 12 species of Aspergillus and five strains of Aspergillus flavus. The 12 species were correctly identified but only a $95 \%$ accurate identification was obtained at the strain level. It was also pointed out that Aspergillus niger could not be distinguished from Aspergillus chevalieri. The authors concluded that the identification of Aspergillus spp. with MALDI-TOF
MS would require a comprehensive database of at least 180 species of Aspergillus. A study showed that different species of Aspergillus, including aflatoxigenic and nonaflatoxigenic spp., could be characterized directly from intact spores ( $\mathrm{Li}$ et al., 2000). However, the authors reported certain discrepancies due to the difficulties encountered to discriminate the spectra obtained with some of the analysed species. A database including the reference spectra of 28 clinically relevant Aspergillus species was engineered in a recent study by including species-specific fingerprints of both young and mature colonies of reference strains (Alanio et al., 2010). The performance of the database was tested on 124 clinical and 16 environmental Aspergillus isolates resulting in a $98.6 \%(138 / 140)$ correct identification with $100 \%$ specificity ( $0 \%$ misidentification). This study has demonstrated that a complete fingerprint database including spectra from both young and mature fungal colonies makes MALDI-TOF a robust method for Aspergillus species identification regardless of the maturity of the tested isolates.

The identification of multiple Fusarium spp. has also been demonstrated by various studies. In the study by Marinach-Patrice et al. (2009), 62 strains or isolates belonging to nine Fusarium spp. were subjected to both molecular identification and MALDI-TOF MS analysis. Following updating of the BioTyper database with 13 strains of five Fusarium spp., 57 (92\%) strains were correctly identified using MALDI-TOF MS analysis. Only one Fusarium pseudonygamai isolate was misidentified and four Fusarium isolates were not identified due to absence of reference spectra in the database. MALDI-TOF MS was also used successfully to identify five mycotoxin-producing Fusarium spp. by direct analysis of spores which yielded highly reproducible MS profiles (Kemptner et al., 2009).

\section{Dermatophytes}

The most important clinical fungal dermatophytes species, T. rubrum, Trychophyton interdigitale, Trychophyton tonsurans, and Arthroderma benhamiae, originating from skin and nail were recently identified using the Saramis database (Erhard et al., 2008). Except for one T. rubrum strain, a high level of confidence $(99.9 \%)$ was obtained in this study where sufficient MS spectra were used to produce a super-spectrum for each species.

\section{Problematic identifications}

Similar to bacteria, absence of identification or misidentification of fungal species by MALDI-TOF MS analysis are essentially due to absence, mistakes or incomplete reference spectra in the database (Table 2). High quality 
MS spectra are usually easily obtained with both fungal hyphae and spores following the manufacturer's instruction or based on the recommendation of reference studies. For instance, because of their cell wall structure, yeasts need an extraction step to yield a valid score of identification by MALDI-TOF MS. In the study of Bizzini et al. (2010) only $4 \%(1 / 24)$ of the valid results were obtained by direct application of the colony on the MALDI plate and an extraction method prior to analysis by MALDI-TOF was also shown to be mandatory to obtain appropriate spectra in the study performed by van Veen et al. (2010). The spectra of several Penicillium spp. obtained from bead beating fungal samples resuspended in an acidic solvent prior to MALDI-TOF analysis was more discriminative (abundant peaks in the range 5000 $20000 \mathrm{~m} / \mathrm{z}$ ) than spectra obtained directly from intact spores (range of 2600-7378 m/z) (Chen \& Chen, 2005; Hettick et al., 2008a, b). However, Valentine et al. (2002) identified A. niger, Rhizopus oryae, Trichoderma reesei, and Phanerochaete chrysosporium using either intact spores, hyphae or extracts showing that intact cells, sonicated cells, and acid-treated cells yielded similar spectra.

The main problem is that, unfortunately, very few reference spectra are currently included in the database of commercially available MALDI-TOF MS systems. Most of the studies showing that the MALDI-TOF MS identification is a powerful system for the characterization and identification of fungi have built and used their own reference spectra database and have developed their own sample preparation techniques. There is thus still a lack of standardized extraction protocols regarding filamentous fungi.

In addition, the spectral signal of filamentous fungi may be strongly influenced by the phenotype of the fungus including basidiospore, monokaryon, dikaryon, fruiting body, surface mycelium, strands and substrate mycelium. Moreover, vegetative mycelium grown on agar shows multiple zones that correspond to different ages or developmental stages. These variations may thus influence the spectral reproducibility of the same isolate and a comprehensive database of filamentous fungi should include MS fingerprints of several different developmental forms to guarantee high yields and accuracy of identification as demonstrated by Alanio et al. (2010).

\section{Direct identification from samples}

Given the accuracy of MALDI-TOF for bacterial identification, this technology might be directly applied to some clinical samples, such as blood, urine, cerebrospinal fluid, pleural fluid, peritoneal liquid, and synovial fluid. The major limitation is the amount of bacteria present in the samples and the limit of detection of cur- rent MALDI-TOF protocols. To circumvent this difficulty, large volumes are used for blood and urine and an additional enrichment by culture is available for blood (see paragraphs below). Regarding cerebrospinal fluid, Nyvang Hartmeyer et al. (2010) successfully identified $S$. pneumoniae $30 \mathrm{~min}$ after receiving a sample supporting the proof-of-concept. However, practically, bacterial identification from cerebrospinal fluid, strongly limited by the low bacterial load and the limited volume available, is yet not applicable in routine diagnostic laboratories.

\section{Blood (hemoculture)}

Bloodstream infection, septic shock, and endocarditis represent severe diseases with important mortality and morbidity. Blood culture represents the best way to establish the etiology of such infections and to guide antimicrobial treatment. This is important since rapid and appropriate antimicrobial therapy is pivotal to reduce poor outcome (Kollef, 2000). Indeed, the fatality rate was $20 \%$ for bloodstream infection patients treated with appropriate therapy and $34 \%$ for patients treated with inappropriate therapy (Leibovici et al., 1998). The rapid notification of the Gram stain result from positive blood culture has also a positive impact for adaptation of antimicrobial regimen (Munson et al., 2003). Consequently, the precise identification of a microorganism isolated from positive blood culture early after Gram stain notification will likely help clinician to better adapt the antimicrobial therapy. As an example, the impact on the choice of the antibiotic will likely be significant when Gram-positive cocci are identified from blood cultures, as the antibiotic susceptibility of Enterococcus faecium is clearly different from that of alpha-hemolytic streptococci.

Quantitative blood cultures have demonstrated that bacterial load during bloodstream infection is very low in adults, often $<1-10$ colony forming unit $\mathrm{mL}^{-1}$. In practice, blood samples are inoculated into bottles containing broth media and incubated in automated instruments monitoring $\mathrm{CO}_{2}$ concentrations released during bacterial growth. At the automated growth detection time, the bacterial load may reach a heavy growth up to $10^{6}-10^{8}$ colony forming units $\mathrm{mL}^{-1}$. In our laboratory, Enterobacteriaceae, $P$. aeruginosa, and aerobic Gram-positive cocci were generally detected when present at $10^{7}$ bacteria $\mathrm{mL}^{-1}$. Such bacterial concentration might be adequate to allow accurate bacterial identification using MS.

However, the blood culture bottle fluid represent a complex solution with multiple nonbacterial proteins isolated from patient's blood and nutrient growth media. These proteins alter the specific bacterial MS profile obtained by MALDI-TOF and have a detrimental effect 
on the performance of algorithm used to query the database containing bacterial MS profiles.

The preparation of a bacterial pellet from positive blood culture includes a differential centrifugation step to discard blood cells, an erythrocyte lysis step and a subsequent washing step to remove additional nonbacterial components. Application of this protocol allows the identification in $<1 \mathrm{~h}$ when compared with overnight growth of bacteria required to obtain pure colonies for biochemical identification.

Recent studies (Table 3) have shown that a correct identification by MALDI-TOF is obtained in $>80 \%$ of cases starting from blood culture bottles. The results varied according to the bacterial pellet preparation protocol and the type of microorganism present in blood cultures. Using ammonium chloride as lysing agent, 89\% of Gramnegative bacteria and $73 \%$ of Gram-positive bacteria (i.e. $90 \%$ for Staphylococci and 33\% for Streptococci) were correctly identified at the species level (Prod'hom et al., 2010). No identification was observed in $21 \%$ of cases. The lower performance of MALDI-TOF for Gram-positive bacteria and particularly Streptococci has also been observed in other studies (Table 3). Similar to MALDITOF identifications from pure microbial isolates, several hypotheses have been suggested to explain discordant results obtained from blood cultures: (1) the close relatedness of the different species especially within Streptococci, notably within S. mitis group (i.e. S. pneumoniae, S. mitis, Streptococcus sanguinis, Streptococcus oralis) conferring closely related MALDI-TOF spectrum profiles, (2) the cell wall composition of Gram-positive bacteria conferring resistance to lysis. In addition, the presence of capsules in different species (S. pneumoniae, Haemophilus influenzae, K. pneumoniae) may also explain the lower performance of MALDI-TOF.

The performance of MALDI-TOF for the identification of fungi in blood culture is low. In one study (Ferreira et al., 2010c), no fungi (0/18) were identified at the species level and only one at the genus level. This poor performance is attributed to the relatively low load of fungi observed in positive blood culture and to the presence of residual blood protein which co-migrates during the MALDI-TOF assay, which impairs the performance of the diagnostic algorithm. To circumvent this detrimental effect, a reference database of fungi obtained from blood culture spiked with fungi was established to obtain correct identification at the species level (Marinach-Patrice et al., 2010).

Limitation of the MALDI-TOF identification was also observed for mixed bloodstream infection, where only one bacterium could be identified (La Scola \& Raoult, 2009; Moussaoui et al., 2010; Szabados et al., 2011).

The impact of the broth on the spectral quality and thus on the rate of identification has been analysed in several studies. The first published studies have used bottles adapted to the BACTEC system (Becton Dickinson, Franklin Lakes, NJ). More recently, bottles with and without charcoal adapted to Bact/ALERT automated instruments have been tested (bioMérieux). In this system, charcoal is used to inactivate antimicrobial agents present in the patient's blood. In one study, the rate of identification using MALDI-TOF was 30\% without charcoal and decreased to only $8 \%$ when charcoal was present (Szabados et al., 2011). Another study compared the performance of identification using MALDI-TOF with positive blood culture obtained from three automated systems: BACTEC, VERSATREK (Trek Diagnostic Systems, Cleveland, $\mathrm{OH}$ ) and BactT/ALERT. The rate of direct identification of bacteria cultured in these three automated blood culture devices were $76 \%, 69 \%$, and $62 \%$ for the investigated samples, respectively (Romero-Gomez \& Mingorance, 2011).

The importance of the protein extraction method was compared with the so-called intact cell method, which consist in the direct deposition on MALDI plate of bacterial pellet obtained from positive blood culture. In one study, the performance of MALDI-TOF identification at the species level was $47 \%$ for the intact cell method compared to $76 \%$ for the protein extraction method (Ferreira et al., 2010a,b,c). The simple extraction method used in this study improves significantly the performance of MALDI-TOF identification rate. In our laboratory, we now use this approach on a routine basis, with a turnaround time estimated to be about $1 \mathrm{~h}$. However, to be efficient and have such a low turnaround time, there is a need to prioritize identification of bacteria isolated from blood cultures over other routine applications of the MALDI-TOF. Thus, this activity somehow delays other microbial identifications, as shown in Fig. 4.

In conclusion, the application of MALDI-TOF identification to microorganism pellets obtained from positive blood culture allows a rapid identification of microorganisms growing in blood culture which is important for the management of bloodstream infections.

\section{Urine}

As the bacterial amount in urine taken from patients with urinary tract infection is often $\geq 10^{5}$ bacteria $\mathrm{mL}^{-1}$, the use of MALDI-TOF directly on urine has been investigated by numerous groups. However, as only about $1-2 \mu \mathrm{L}$ of liquid may be deposited on the MALDI-TOF microplate, results were not accurate when untreated urine are directly deposited and thus various pretreatment steps have been tested with different outcomes. Using two consecutive centrifugation steps (low speed to remove leukocytes and high speed to collect the bacteria), Ferreira 


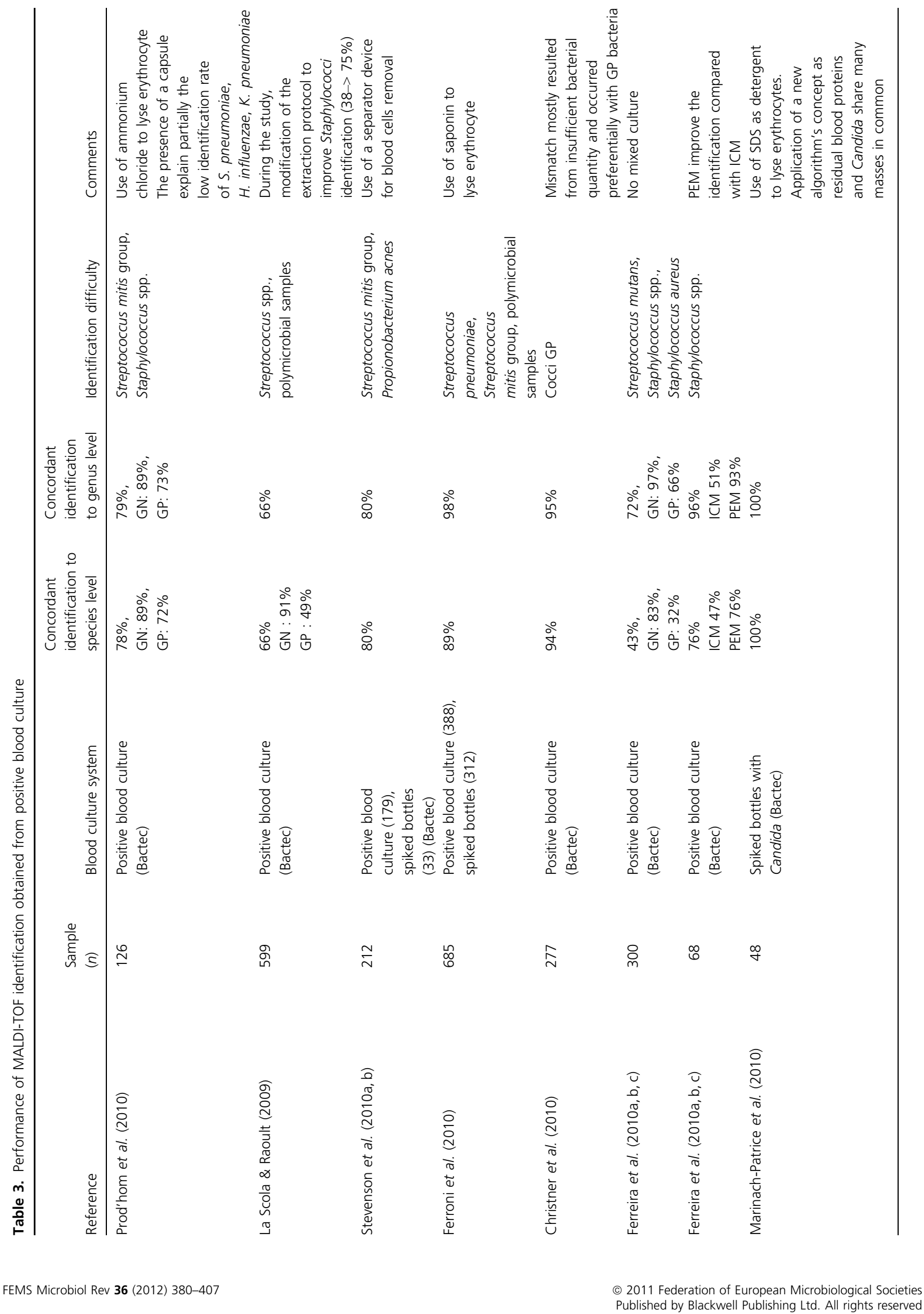




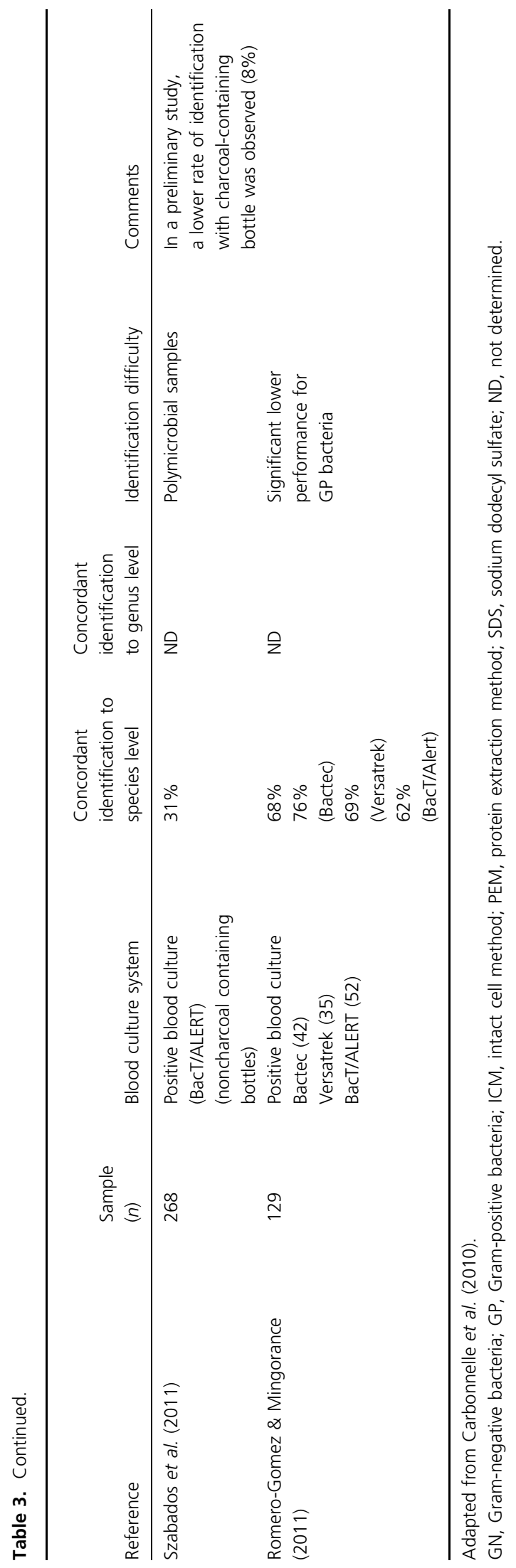

et al. (2010a, b, c) could accurately identify as much as $94.2 \%$ of bacteria. However, they only included in their study urine with $>10^{5}$ bacteria $\mathrm{mL}^{-1}$. When investigating a simplified protocol in our laboratory for the identification of E. coli (single centrifugation step), the results was acceptable when the bacterial concentration was of $10^{7}$ and $10^{8}$ bacteria $\mathrm{mL}^{-1}$ with $69 \%$ and $70 \%$ of samples being accurately identified at the species level (score $>2)$. However, the yield was poor with lower bacterial load (Fig. 5). Given the huge amount of urine processed on a daily basis, the low value of early identification and the requirement of bacterial isolation in pure culture for antibiotic susceptibility testing, it appears that the MALDITOF on urine is not cost-effective and not efficient enough to be implemented directly on urine samples. Indeed, as most urinary isolates are E. coli (> 80\% among uncomplicated cystitis occurring in young women and about $50 \%$ in complicated urinary tract infections), the use of a chromogenic agar (i.e. Urid; bioMérieux) coupled with simple phenotypic tests such as indole represents a simpler way to identify most strains. MALDI-TOF will then be mainly used to identify the remaining species starting from colonies.

\section{Maintenance and quality controls}

The MALDI-TOF MS is increasingly used in clinical diagnostic laboratory for microbial identification with reliable results for bacterial identification at the species level.

MALDI-TOF results may, however, be impaired by problems arising during extraction, for instance (1) when testing encapsulated bacteria (S. pneumoniae, K. pneumoniae), (2) when testing bacteria such as Streptomyces, that exhibit a particular cell wall that reduces the yield of protein extraction, (3) when the extraction protocol is not properly conducted, or (4) when the reagents used for extraction are outdated or impaired by inadequate storage. Problems (1) and (2), due to intrinsic bacterial properties, may only be circumvented by the development of specific extraction protocols and problems (3) and (4) might be prevented by an adequate quality program. The performance of the extraction step and of the MALDITOF mass spectrometer may be checked by routinely testing a few selected bacterial strains, for which spectra are available in the database. This control should ideally be done in parallel with and without a specific extraction step. We thus implemented in our laboratory routine internal quality controls that test the quality of the extraction step on two different bacterial species (E. coli ATCC 25922 and S. aureus ATCC 25923). To set-up this quality control, we first investigated the reproducibility of the extraction step (see Fig. 2 and paragraph on reproducibility). This allowed us to define conserved peaks 


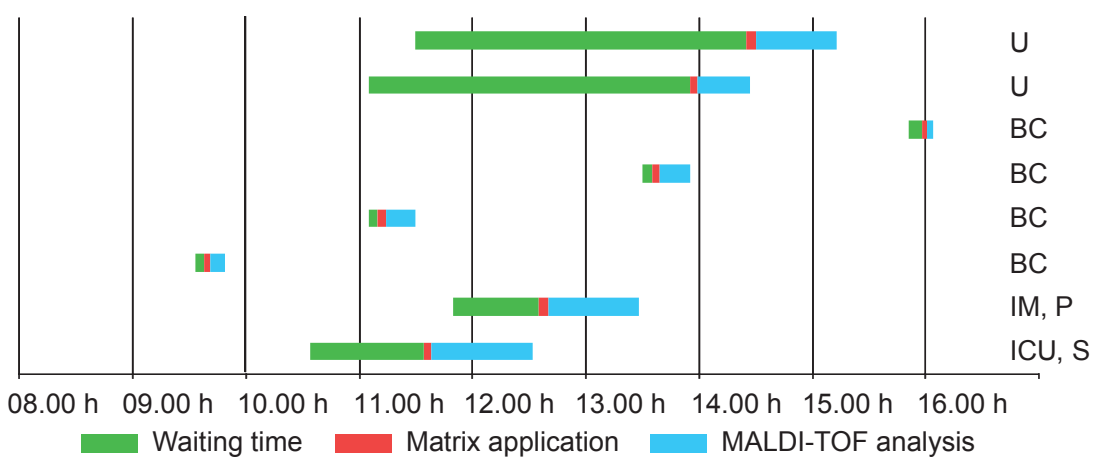

Fig. 4. Importance of the organization of a working day to optimize time to results. Each line represents a MALDI-TOF run, with the waiting time for equipment availability, the time required to prepare the target layout, and the time of the MALDI-TOF running process. In this example of a working day, eight MALDI-TOF target plates have been used to analyse multiple clinical samples [ICU, S: intensive care unit and surgery (one run); IM, P: internal medicine, pediatry and others (one target plate); BC: blood cultures (four runs); U: urine (two runs)]. Urgent samples such as blood cultures are directly processed while colonies identification from agar cultures are processed by batch. The processing of the samples is organized to guarantee the optimal use of the MALDI-TOF device during the working day.

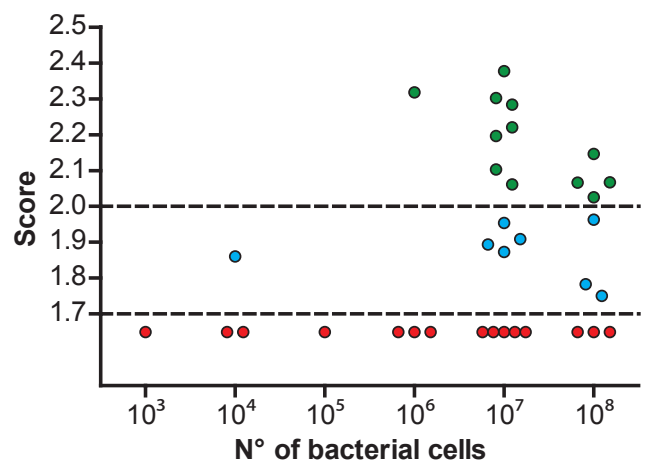

- Score $>2.0$ (accurate identification at the species level)

- $1.7>$ score $<2.0$ (moderate identification at the genus level)

- Score $<1.7$ (no identification)

Fig. 5. Escherichia coli identification yield in urine samples. Five milliliters of urine samples positive by microscopy were centrifuged to concentrate and collect the bacteria. The pellet was resuspended in $200 \mu \mathrm{L}$ water and subjected to protein extraction with ethanol and formic acid prior deposition on the microplate. The graph shows the identification yield according to the bacterial load per $\mathrm{mL}$.

(peaks present in 10/10 replicates). Then, we routinely tested once a week both bacterial species. As score values were always above 2 and to obtain a better expression of the quality of the extraction, we decided to report the proportion of conserved peaks detected, considering a peak as present only when its intensity was above 200 . Indeed, the rate of detection of conserved peaks reflects not only the quality of the sample but also the protein yield and the spectral quality (Fig. 6).

MALDI-TOF results may also be impaired by inadequate deposit of the sample on the microplate and by poor cleaning of the microplate between runs. Inadequate deposit of samples is relatively rare when starting from bacterial colonies and the learning curve is rapid with most laboratory technicians being already experts in depositing appropriate amount of bacteria after only a few training days. However, erroneous identification may occur due to well inversions, especially when large series are processed and when stress is increased by human resources shortage.

Poor cleaning of the microplate is a problem only encountered by Bruker users as Shimadzu users will use disposable MALDI-TOF plates. Bruker commonly propose to use trichlorofluoroacteate (TFA) or guanidium to clean microplates between usages. As TFA is associated with significant occupational hazard (eye, skin, and respiratory toxicity), we used in our laboratory an alternative protocol to clean MALDI-TOF microplate. This protocol, initially proposed by Bruker, which mainly uses ethanol and mechanical cleaning of target plates, is, however, insufficient to properly clean MALDI-TOF microplates. Indeed, when investigating cleaned plates by testing them only in presence of matrix, we could obtain some accurate identification with score $>2$ and corresponding to the same bacterial species investigated the day before. Such accurate identifications obtained after plate cleaning could rarely correspond to wells where some material was still present (Fig. 7a, wells C4, E3, and E4), but also occurred in apparently clean wells. Thus, a systematic control of the microplates should be done and the cleaning protocol adapted when necessary. Noteworthy, disposable microplates are now also available for Bruker users.

MALDI-TOF results may also be impaired by technical problems and/or poor maintenance of the MALDI-TOF device. To identify possible technical problems and to recalibrate the MS apparatus, we routinely use in Lausanne the calibration control proposed by Bruker. This control 

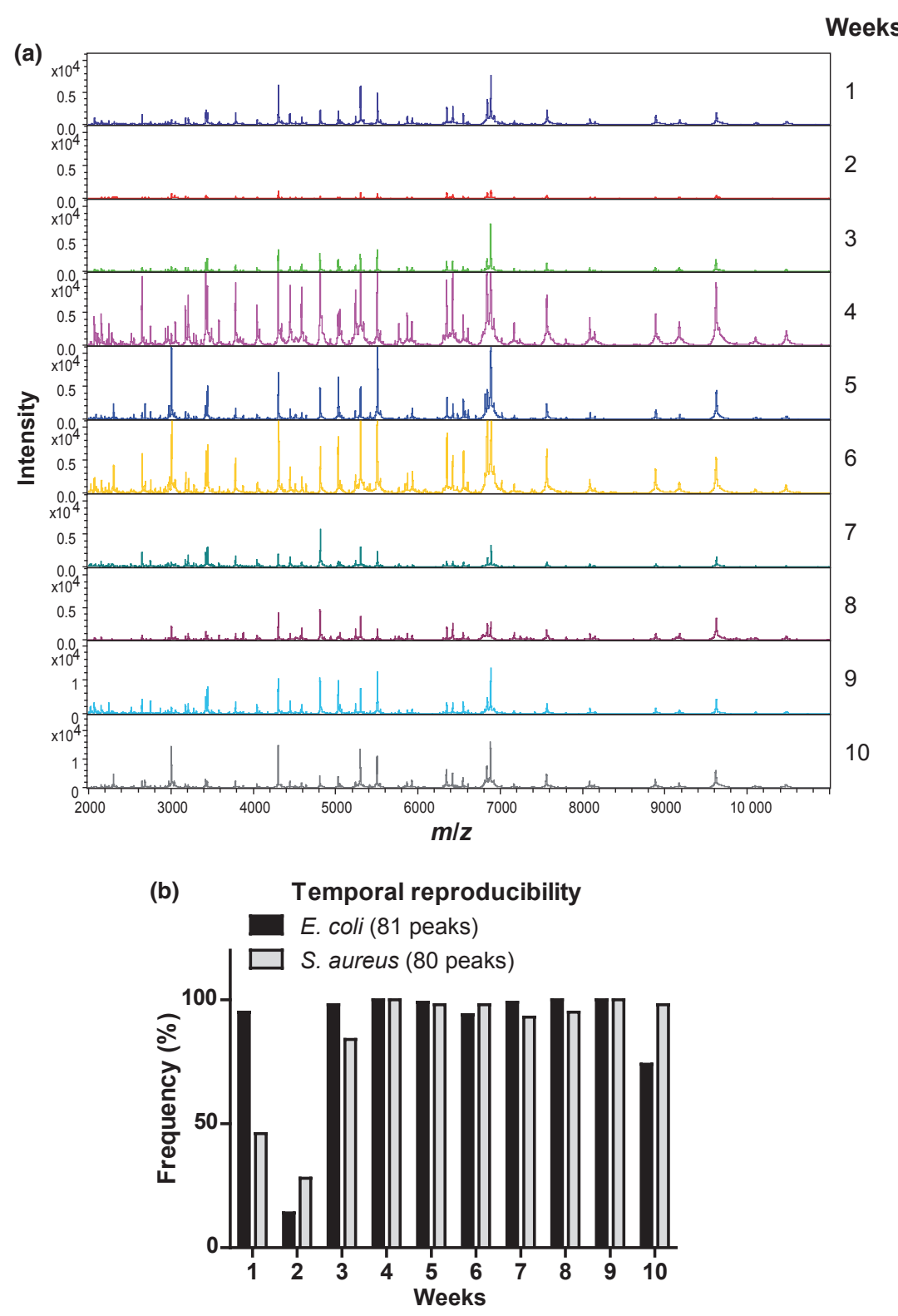

Fig. 6. Importance of the maintenance and quality controls of the MALDI-TOF device demonstrated by a follow-up of the temporal reproducibility. (a) Spectral fingerprint of Staphylococcus aureus quality controls during a 10-week control period. (b) Percentage of conserved peaks during a 10-week control period. Escherichia coli and Staphylococcus aureus quality controls fingerprints were compared with a set of conserved peaks (81 and 80 , respectively). The poor performance observed during week 1-3 was likely caused by a problem of inadequate sample deposition on the MALDI-TOF MS microplates.

(called BTS) consists of lyophilized E. coli extracts and two supplementary proteins, RNAse A and myoglobin, which respectively exhibit peaks at 13683 and 16952 $\mathrm{m} / \mathrm{z}$ (Fig. 7b). Finally, in the future, external quality control should be implemented.

Appropriate maintenance (Fig. S1) is also essential to warrant accurate bacterial identification. Vacuum failure, and thus MALDI-TOF MS functional disturbance (see Fig. 1), might be observed due to the presence of dust on plastic joints or to the aging of these plastic joints (Fig. S1c and d). Dust exposure of the MALDI-TOF apparatus might be reduced by placing the mass spectrometer in a quiet area, without drafts. Carbonization of bacteria embedded in the matrix material following each laser pulse is also a source of concern, as the laser source may be soiled (Fig. S1d). With the Bruker instrument, the level of dirt present on the laser source may be indirectly estimated according to the number of shots needed to obtain a correct identification. Maintenance should ideally be done before the dirtiness rate reaches $80 \%$, i.e. about four times a year if three to five microplates are tested per day. Of course, frequency of maintenance of the MALDI-TOF should be increased if the apparatus is heavily used or located in a crowded/dusty area.

Despite adequate maintenance and correct procedures, some microbial groups will repeatedly be misidentified due to poor content of some databases. Thus, it appears critical not only to implement a quality control program 
(a)

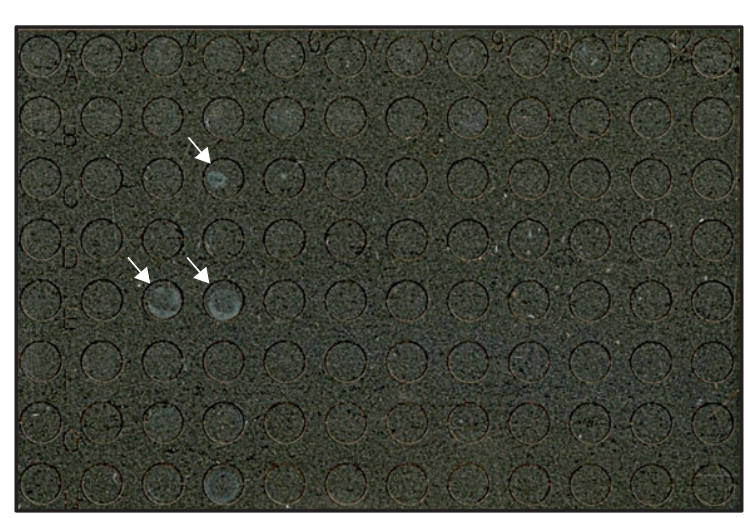

(b)

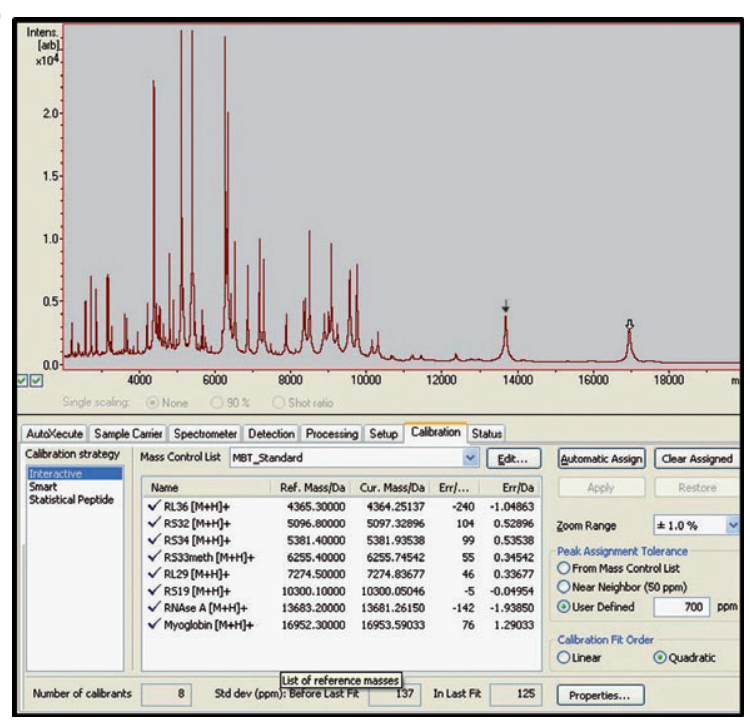

Fig. 7. Quality control for MALDI-TOF MS. (a) Presence of residual materials on some wells (especially C4, E3, and E4, indicated by white arrows) of a MALDI-TOF microplate after a routine wash, highlighting the importance of careful wash after each usage; (b) mass spectra obtained with the Bruker BST control, that consists in lyophilized Escherichia coli spiked with RNAse A (black arrow at a $\mathrm{m} / \mathrm{z}$ of 13 683) and myoglobin (white arrow at a $\mathrm{m} / \mathrm{z}$ of 16 952); in the lower part of the panel, the list of the eight proteins that should be present to validate the run and their expected and observed $\mathrm{m} / \mathrm{z}$ values.

targeting routine procedure but also to incrementally improve the quality of the database. In conclusion, quality controls might help to improve the quality of proteins extraction, MALDI-TOF analysis, and completeness of databases. This will thus further improve the accuracy and usefulness of MALDI-TOF.

\section{Accuracy, time and cost effectiveness}

The MALDI-TOF MS approach represents a new tool that has the potential to replace conventional identification techniques for a majority of routine isolates encountered in clinical microbiology laboratories. The performance of the MALDI-TOF MS approach has been compared in several studies (Seng et al., 2009; Bizzini et al., 2010; Cherkaoui et al., 2010; van Veen et al., 2010) with multiple routine phenotypic identification methods, such as semiautomated Gram staining (Aerospray Wescor ${ }^{\circledR}$; Elitech), catalase and oxidase determination tests, automated identification by $\operatorname{Vitek}^{\circledR}$ (bioMérieux), the Api Anaérobie BioMérieux $^{\circledR}$ identification strip for anaerobes (bioMérieux), the Slidex Staph plus system (bioMérieux). These studies showed that the MALDI-TOF technique has a high accuracy for most microbial identifications and performed equally as well as or better than conventional techniques. For instance, van Veen et al. (2010) showed that significantly more bacterial isolates could be identified to the species level by MALDI-TOF MS, with a special higher performance for staphylococci and bacteria from the HACCEK group. Similarly, Bader et al. (2010) have shown that identification of yeast species with MALDI-TOF MS systems gave an overall species identification rate $(97.9 \%$ for Bruker and $96.1 \%$ for Shimadzu) that was comparable with the one obtained with the biochemical tests (96.9\%).

The most striking differences between MALDI-TOF technique and conventional identification methods are observed in the estimated time and costs required for sample identification. The cost of bacterial identification by MALDI-TOF MS was estimated to represent only 17$32 \%$ (around $€ 1.43 /$ sample) of the costs of conventional identification methods (around $€ 4.6-8.23 /$ sample) in the study performed by Seng et al. (2009), which is supported by at least two other prospective studies (Bizzini et al., 2010; Cherkaoui et al., 2010). Cherkaoui et al. (2010) have shown that the reagents required for phenotypic identification using modern automated platforms costs at least around $\$ 10$ per isolate, whereas MS-required reagents do not exceed $\$ 0.50$. The expensive prices of MS instruments are comparable with other common bacteriology laboratory equipment such as automated blood culture and $16 \mathrm{~S}$ sequencing devices but the running costs are significantly cheaper than those of conventional identification methods. Thus, in our laboratory, we estimated that the reagents costs spared during a year are of approximately $€ 40000$ (Table S2). Of course, this cost analysis did not include the cost of maintenance, neither for MALDI-TOF nor for automated phenotypic identification systems such as Vitek.

Compared with conventional identification methods, MALDI-TOF has been shown to confer in most cases a significant gain of both technician working time (preanalytical procedure to prepare samples) and turnaround time (automated analytical procedure to obtain results).

The time needed for bacterial identification from intact cells was 6-8.5 min vs. 5-48 h for conventional identification as estimated by Seng et al. (2009). When an 
extraction step is required, Bizzini et al. (2010) have estimated that the extraction procedure for a single sample takes approximately $6 \mathrm{~min}$, a time per sample that is further reduced during batch processing. The time effectiveness gained with MALDI-TOF identification compared with classical identification approaches is even more accentuated when several isolates are analysed in parallel. As reported by Cherkaoui et al. (2010) the analysis of 10 isolates in parallel can be accomplished in $<15$ min with limiting working time by MS, whereas more than 360 min would be required on an automated system with more hands-on time for each isolate, demonstrating that MALDI-TOF MS provide a reduction of both working and turnaround times. Regarding yeast identification by MALDI-TOF MS, Marklein et al. (2009) showed that this technique required minimal time for technicians to process yeast samples for analysis and to interpret the results. The MALDI-TOF identification procedure from single yeast colonies on the agar plate was generally completed within $10 \mathrm{~min}$ per isolate and within $3 \mathrm{~h}$ for 96 samples. In contrast, the identification of germ tube-negative Candida species by phenotypic methods can require incubation periods of up to $72 \mathrm{~h}$, a significantly longer turnaround time compared with MALDI-TOF. Molecular approaches have been or are currently under development to provide efficient identification of yeasts with a more rapid and reliable efficiency than classical phenotypic methods. However, high-resolution DNA-based molecular techniques such as 26S rRNA or internal transcriber spacer DNA sequencing and real-time PCR assays are expensive and time-consuming and appear in most cases less convenient than MALDI-TOF MS for routine laboratory identifications (Schabereiter-Gurtner et al., 2007; Montero et al., 2008; Seyfarth et al., 2008). Nucleic acidbased identification strategies suffer problematic limitations in terms of (1) technical problems (inhibitory compounds, contamination, separate areas for sample preparation/amplification/analysis), (2) reagent and labor costs, (3) spectrum of species identification in a single assay often limited to a few individual species, and (4) much longer turnaround time than MS. Thus such lengthier, costlier and more labor-intensive alternatives to MALDI-TOF MS are usually reserved for the identification of the small minority of isolates not identified by MS alone or by other conventional phenotypic and/or biochemical identification approaches.

\section{Taxonomy and microbial typing}

\section{Taxonomic usefulness of MALDI-TOF MS}

Taxonomy is the systematic classification of organisms based on their phenotypic, genetic and phylogenetic char- acteristics. Thus, various phenotypic approaches (morphology, biochemical reactions, and sugar assimilation) have been used by microbiologists to classify microorganisms. However, genome analysis through sequencing of bacterial genes or of the entire genome currently represents the gold-standard of microbial taxonomy, although it should always be confronted to phenotypic traits in a polyphasic approach. MALDI-TOF MS represents an additional approach to classify microorganisms based on phenotypic traits. As previously shown in several studies mentioned in this review, MALDI-TOF MS systems give accurate and reproducible results at the species level that are in most cases concordant with genomic identification methods and consequently, MALDI-TOF has the potential to be used in polyphasic taxonomy. For instance, in contrast to housekeeping genes sequencing such as 16SrRNA that provide taxonomical data on a single gene at a time, MALDI-TOF MS fingerprints provide information about multiple protein components that characterize a microorganism. In addition, MALDI-TOF fingerprints provide data of both the presence (conservation/divergence) and the intensity (expression level) that together compose a two dimensional taxonomical asset which offer a better discriminative resolution for microorganism classification.

\section{Microbial typing and identification at the subspecies level}

MALDI-TOF MS allows identification of microorganisms at the species level and sometimes at the subspecies level but several studies have shown that the requirements for MALDI-TOF MS-dependent microbial typing are different and more complex than those required for routine microbial identification. This is a challenge for clinical laboratories that want to use MALDI-TOF MS for routine strain typing. Relatively few biomarkers (5-10 peaks) are usually required for the identification of microbial isolates at the species level, whereas a much larger number of reproducible peaks is needed for subspecies identification (Dieckmann et al., 2008). Many studies cited in this review using conventional MALDI-TOF procedure could not directly identify taxonomic entities like species or subspecies with an accuracy of $100 \%$ without the assistance of DNA-based methods. Microbial typing and thus microbial characterization at the subspecies level required very different sample preparation and analytical procedures (Murray, 2010). As mentioned previously in this review, accurate sample preparation is generally unnecessary for microorganism identification but for strain typing and subspecies identification, a rigorous optimization of testing parameters appears to be crucial. The challenge is to obtain a sufficient number of repro- 
ducible markers with specificities below species-level specificity (Rupf et al., 2005; Vargha et al., 2006; Dieckmann et al., 2008). For instance, the sample preparation procedure (whole cell or protein extraction), the protein concentration, the type of matrix, the sample : matrix ratio, the concentration of acid added to the matrix and the growth medium are examples of technical parameters that can have a significant influence on the MALDI-TOF spectral profile of biomarkers (Vargha et al., 2006; Dieckmann et al., 2008).

The choice of analysis solutions used to process mass spectra can have a significant impact on the power of discrimination and thus on the ability to distinguish closely related isolates. Maximizing reproducibility is also critical for accurate microbial characterization. One of the major limitations of MALDI-TOF-based microbial typing is primarily due to the algorithmic methods used to analyse the protein profiles. Several similarity coefficients can be used to determinate level of similarities. Some account only for peak presence/absence such as the Dice similarity coefficient, whereas others take also in consideration the peak intensities, such as cosine and Pearson productmoment correlation coefficients. The chosen similarity coefficient affects the reproducibility and the discriminatory power of the method. Several studies have demonstrated that the Pearson coefficient appears to be more adequate for the correct classification of microbial isolates. A study by Giebel et al. (2008) showed that the Pearson product-moment correlation coefficient permitted a more accurate classification of Enterococcus spp. isolates than the Dice similarity coefficient. Similarly, the use of the Pearson correlation coefficient allowed a $28 \%$ increase in the rate of correct classification of E. coli isolates (Giebel et al., 2010). Using optimal sample preparation and MALDI conditions for discrimination at the strain level and by using the Pearson coefficient, Vargha et al. (2006) have shown that MALDI-TOF MS offered a better discriminatory power than $16 \mathrm{~S}$ rRNA gene sequencing for the classification at the subspecies level of Arthrobacter isolates. For instance, members of the A. globiformis cluster have $99-100 \%$ sequence similarity, whereas MALDI-TOF MS similarity is 60-95\%.

In some cases, the identification of multiple or single unique subspecies biomarkers have been used to discriminate closely related microbial isolates exhibiting highly similar mass signatures. For instance, five unique and conserved biomarkers ions were identified in environmental E. coli isolates from avian but not from human sources (Siegrist et al., 2007). Similarly, several Listeria monocytogenes serotypes could be separated using discriminating peaks (Barbuddhe et al., 2008).

Despite an increased level of complexity required for microbial subspecies classification, several published stud- ies support the observation that MALDI-TOF MS represents a new promising technological approach for the classification of clinical and environmental isolates. Dieckmann et al. (2008) have successfully classified 126 isolates of Salmonella at the species and subspecies levels by optimizing a procedure that allowed them to obtain more than 300 biomarker peaks ranging from 2 to $>35 \mathrm{kDa}$. They found that out of three matrix mixtures, SA produced the most informative spectra by providing a significant increase of high molecular mass peaks with important subspecies specificity. In addition, simple clustering of mass data from bacterial fingerprints did not initially provide a clear discrimination of the strains at the subspecies level and a bioinformatic approach recently published by Teramoto et al. (2007) had to be used. The approach is a new phylogenetic classification method based on ribosomal protein profiling by MALDI-TOF MS using the bioinformatics-based method for rapid identification of bacteria published by Demirev et al. (1999). Using this approach, the result of the classification of several P. putida strains including different biovars was in agreement with the gyrB gene sequences-based classification.

The determination of serotypes of Shiga toxin-producing E. coli isolates has been achieved by constructing prototype spectra representing different serotype groups (Karger et al., 2011). The prototype spectra were generated by removing masses with low discriminative significance, which is a process comparable with the generation of super-spectra proposed by the Saramis software. The generation of prototype spectra allowed a reduction of incorrect assignments down to $0.7 \%$ compared to the $31 \%$ incorrect assignments observed when unfiltered mass spectra were used. Unlike restriction fragment length polymorphism analysis, this analytical methodology could not achieve a differentiation below the serotype level.

The typing of several microorganisms, such as Staphylococcus and Listeria species, for epidemiological studies require the use of various conventional techniques such as pulsed-field gel electrophoresis (PFGE), amplified fragment length polymorphism analysis and multilocus sequence analysis (MLSA). These gold-standard techniques provide accurate classification of microorganism but suffer from important time and cost investments. For instance, only a few hours are required to obtain results by MALDI-TOF MS whereas several days are necessary to collect PFGE data. In addition, these methods are technically relatively complex and have to be usually performed by experienced technicians.

Several Staphylococcus studies have developed standardized methods to achieve reliable and reproducible species level identification and sub-typing from MALDI-TOF fingerprints (Edwards-Jones et al., 2000; Walker et al., 2002; 
Jackson et al., 2005). When performed under careful experimental conditions, MALDI-TOF MS has been used to discriminate between methicillin-resistant (MRSA) and methicillin-susceptible $S$. aureus strains and to subtype MRSA strains. Thus, compared with conventional antimicrobial susceptibility test methods or gene sequencing techniques, these studies have demonstrated that MALDI-TOF MS represents a fast and cheap approach to accurately differentiate $S$. aureus strains. Unfortunately, no comparison of MALDI-TOF MS with PFGE has been performed to demonstrate that these two methods would give similar results. However, Barbuddhe et al. (2008) have used MALDI-TOF to accurately identify 146 strains of different Listeria species and correctly classified all L. monocytogenes serotypes in agreement with PFGE, which is one of the most common subtyping techniques used to classify L. monocytogenes serotypes. Similarly, Fujinami et al. (2010) have demonstrated that MALDI-TOF MS and PFGE gave similar accurate identification of epidemiologic Legionella strains. Hazen et al. (2009) have demonstrated that MALDI-TOF MS could be used to discriminate between several Vibrio parahaemolyticus strains in replacement of PFGE or MLSA. Thus, these studies showed that MALDITOF represents a new promising alternative approach to other demanding conventional methods such as PFGE and MLSA for microbial subtyping.

Overall, the ultimate goal would be to use MALDITOF for a rapid prospective typing at the time of identification, which should significantly benefit to hospital epidemiology and to infection control measures that have to be applied to prevent dissemination of pathogens. Three recent studies have demonstrated that by applying subtle minor changes in the set-up generally used in routine diagnostics, MALDI-TOF MS allowed a reproducible discrimination of major MRSA lineages (Wolters et al., 2011), an identification of Salmonella enterica subsp. enterica serovars (Dieckmann \& Malorny, 2011) and a differentiation between $c f i A$-negative and $c f i$-positive Bacteroidis fragilis isolates (Wybo et al., 2011). These studies demonstrate that for several microbial species, minor changes in standardized procedures such as improved algorithm and user-friendly softwares applied in routine diagnostics will allow the use of MALDI-TOF MS for rapid and inexpensive microbial typing. This could significantly improve the approaches currently used to monitor epidemiological outbreaks and pathogen surveillance.

\section{Conclusion}

MALDI-TOF represents a very appealing new microbial identification technology that is efficient, rapid, cheap, and easy to use. This explains why MALDI-TOF MS can be successfully used in clinical diagnostic laboratory for microbial identification starting from subcultures on agar plates and broth media but also directly from positive blood cultures and to a lesser extent from clinical samples such as urine. The application of MALDI-TOF at the subspecies level in typing is promising but still needs further improvement including instrument sensitivity, database quality, and postrun analysis methods. Overall, a MALDI-TOF MS will be soon present in most diagnostic laboratories as, despite the significant cost of the instrument and for maintenance, running costs and consumables are much lower than those for other conventional methods, rendering this technology a worthy quantum leap tool.

\section{Acknowledgements}

We thank Myriam Corthesy for technical support. G.G. is supported by the Leenards Foundation through a career award entitled 'Bourse Leenards pour la relève académique en médecine clinique à Lausanne’.

\section{References}

Aebersold R \& Mann M (2003) Mass spectrometry-based proteomics. Nature 422: 198-207.

Alanio A, Beretti JL \& Dauphin B et al. (2010) Matrix-assisted laser desorption ionization time-of-flight mass spectrometry for fast and accurate identification of clinically relevant Aspergillus species. Clin Microbiol Infect 17: 750-755.

Anhalt JP \& Fenselau C (1975) Identification of bacteria using mass spectrometry. Anal Chem 47: 219-225.

Arnold RJ, Karty JA, Ellington AD \& Reilly JP (1999) Monitoring the growth of a bacteria culture by MALDI-MS of whole cells. Anal Chem 71: 1990-1996.

Bader O, Weig M, Taverne-Ghadwal L, Lugert R, Gross U \& Kuhns M (2010) Improved clinical laboratory identification of human pathogenic yeasts by matrix-assisted laser desorption ionization time-of-flight mass spectrometry. Clin Microbiol Infect in press, DOI: 10.1111/j.1469-0691.2010. 03398.x

Barbuddhe SB, Maier T, Schwarz G et al. (2008) Rapid identification and typing of listeria species by matrixassisted laser desorption ionization-time of flight mass spectrometry. Appl Environ Microbiol 74: 54025407.

Bernardo K, Pakulat N, Macht M et al. (2002) Identification and discrimination of Staphylococcus aureus strains using matrix-assisted laser desorption/ionization-time of flight mass spectrometry. Proteomics 2: 747-753.

Bessede E, Angla-Gre M, Delagarde Y, Sep Hieng S, Menard A \& Megraud F (2011) Matrix-assisted laser-desorption/ ionization biotyper: experience in the routine of a University hospital. Clin Microbiol Infect 17: 533-538. 
Bizzini A \& Greub G (2010) Matrix-assisted laser desorption ionization time-of-flight mass spectrometry, a revolution in clinical microbial identification. Clin Microbiol Infect 16: 1614-1619.

Bizzini A, Durussel C, Bille J, Greub G \& Prod'hom G (2010) Performance of matrix-assisted laser desorption ionizationtime of flight mass spectrometry for identification of bacterial strains routinely isolated in a clinical microbiology laboratory. J Clin Microbiol 48: 1549-1554.

Bizzini A, Jaton K, Romo D, Bille J, Prod'hom G \& Greub G (2011) Matrix-assisted laser desorption ionization-time of flight mass spectrometry as an alternative to $16 \mathrm{~S}$ rRNA gene sequencing for identification of difficult-to-identify bacterial strains. J Clin Microbiol 49: 693-696.

Blondiaux N, Gaillot O \& Courcol RJ (2010) [MALDI-TOF mass spectrometry to identify clinical bacterial isolates: evaluation in a teaching hospital in Lille]. Pathol Biol (Paris) 58: $55-57$.

Cain TC, Lubman DM \& Webber WJ (1994) Differentiation of bacteria using protein profiles from MALDI-TOF/MS. Rapid Commun Mass Spectrom 8: 1026-1030.

Carbonnelle E, Beretti JL, Cottyn S, Quesne G, Berche P, Nassif X \& Ferroni A (2007) Rapid identification of Staphylococci isolated in clinical microbiology laboratories by matrix-assisted laser desorption ionization-time of flight mass spectrometry. J Clin Microbiol 45: 2156-2161.

Carbonnelle E, Mesquita C \& Bille E et al. (2010) MALDITOF mass spectrometry tools for bacterial identification in clinical microbiology laboratory. Clin Biochem 44: 104-109.

Chen HY \& Chen YC (2005) Characterization of intact Penicillium spores by matrix-assisted laser desorption/ ionization mass spectrometry. Rapid Commun Mass Spectrom 19: 3564-3568.

Cherkaoui A, Hibbs J, Emonet S, Tangomo M, Girard M, Francois P \& Schrenzel J (2010) Comparison of two matrixassisted laser desorption ionization-time of flight mass spectrometry methods with conventional phenotypic identification for routine identification of bacteria to the species level. J Clin Microbiol 48: 1169-1175.

Christner M, Rohde H, Wolters M, Sobottka I, Wegscheider K \& Aepfelbacher M (2010) Rapid identification of bacteria from positive blood culture bottles by use of matrix-assisted laser desorption-ionization time of flight mass spectrometry fingerprinting. J Clin Microbiol 48: 1584-1591.

Claydon MA, Davey SN, Edwards-Jones V \& Gordon DB (1996) The rapid identification of intact microorganisms using mass spectrometry. Nat Biotechnol 14: 15841586.

Conway GC, Smole SC, Sarracino DA, Arbeit RD \& Leopold PE (2001) Phyloproteomics: species identification of Enterobacteriaceae using matrix-assisted laser desorption/ ionization time-of-flight mass spectrometry. J Mol Microbiol Biotechnol 3: 103-112.

Cotter RJ (1997) Time-of-flight Mass Spectrometry: Instrumentation and Applications in Biological Research. American Chemical Society, Washington, DC.
Dai Y, Li L, Roser DC \& Long SR (1999) Detection and identification of low-mass peptides and proteins from solvent suspensions of Escherichia coli by high performance liquid chromatography fractionation and matrix-assisted laser desorption/ionization mass spectrometry. Rapid Commun Mass Spectrom 13: 73-78.

Demirev PA, Ho YP, Ryzhov V \& Fenselau C (1999) Microorganism identification by mass spectrometry and protein database searches. Anal Chem 71: 27322738.

Dieckmann R \& Malorny B (2011) Rapid screening of epidemiologically important Salmonella enterica subsp. enterica serovars using Whole-Cell MALDI-TOF mass spectrometry. Appl Environ Microbiol 77: 4136-4146.

Dieckmann R, Helmuth R, Erhard M \& Malorny B (2008) Rapid classification and identification of salmonellae at the species and subspecies levels by whole-cell matrix-assisted laser desorption ionization-time of flight mass spectrometry. Appl Environ Microbiol 74: 7767-7778.

Domon B \& Aebersold R (2006) Mass spectrometry and protein analysis. Science 312: 212-217.

Dupont C, Sivadon-Tardy V, Bille E et al. (2010) Identification of clinical coagulase-negative staphylococci, isolated in microbiology laboratories, by matrix-assisted laser desorption/ionization-time of flight mass spectrometry and two automated systems. Clin Microbiol Infect 16: 998-1004.

Edwards-Jones V, Claydon MA, Evason DJ, Walker J, Fox AJ \& Gordon DB (2000) Rapid discrimination between methicillin-sensitive and methicillin-resistant Staphylococcus aureus by intact cell mass spectrometry. J Med Microbiol 49: 295-300.

von Eiff C, Peters G \& Heilmann C (2002) Pathogenesis of infections due to coagulase-negative staphylococci. Lancet Infect Dis 2: 677-685.

Emonet S, Shah HN, Cherkaoui A \& Schrenzel J (2010) Application and use of various mass spectrometry methods in clinical microbiology. Clin Microbiol Infect 16: 1604-1613.

Erhard M, Hipler UC, Burmester A, Brakhage AA \& Wostemeyer J (2008) Identification of dermatophyte species causing onychomycosis and tinea pedis by MALDI-TOF mass spectrometry. Exp Dermatol 17: 356-361.

Fenselau C \& Demirev PA (2001) Characterization of intact microorganisms by MALDI mass spectrometry. Mass Spectrom Rev 20: 157-171.

Ferreira L, Sanchez-Juanes F, Munoz-Bellido JL \& GonzalezBuitrago JM (2010a) Rapid method for direct identification of bacteria in urine and blood culture samples by matrixassisted laser desorption ionization time-of-flight mass spectrometry: intact cell vs. extraction method. Clin Microbiol Infect 17: 1007-1012.

Ferreira L, Sanchez-Juanes F, Gonzalez-Avila M, CembreroFucinos D, Herrero-Hernandez A, Gonzalez-Buitrago JM \& Munoz-Bellido JL (2010b) Direct identification of urinary tract pathogens from urine samples by matrix-assisted laser desorption ionization-time of flight mass spectrometry. J Clin Microbiol 48: 2110-2115. 
Ferreira L, Sanchez-Juanes F, Guerra IP, Garcia Garcia MI, Sanchez JE, Gonzalez-Buitrago JM \& Bellido JL (2010c) Microorganisms direct identification from blood culture by Maldi-Tof mass spectrometry. Clin Microbiol Infect 17: 546551.

Ferroni A, Suarez S, Beretti JL et al. (2010) Real-time identification of bacteria and Candida species in positive blood culture broths by matrix-assisted laser desorption ionization-time of flight mass spectrometry. J Clin Microbiol 48: 1542-1548.

Fujinami Y, Kikkawa HS, Kurosaki Y, Sakurada K, Yoshino M \& Yasuda J (2010) Rapid discrimination of Legionella by matrix-assisted laser desorption ionization time-of-flight mass spectrometry. Microbiol Res 166: 77-86.

Giebel RA, Fredenberg W \& Sandrin TR (2008) Characterization of environmental isolates of Enterococcus spp. by matrix-assisted laser desorption/ionization time-offlight mass spectrometry. Water Res 42: 931-940.

Giebel R, Worden C, Rust SM, Kleinheinz GT, Robbins M \& Sandrin TR (2010) Microbial fingerprinting using matrixassisted laser desorption ionization time-of-flight mass spectrometry (MALDI-TOF MS) applications and challenges. Adv Appl Microbiol 71: 149-184.

Girault S, Chassaing G, Blais JC, Brunot A \& Bolbach G (1996) Coupling of MALDI-TOF mass analysis to the separation of biotinylated peptides by magnetic streptavidin beads. Anal Chem 68: 2122-2126.

Graham R, Graham C \& McMullan G (2007) Microbial proteomics: a mass spectrometry primer for biologists. Microb Cell Fact 6: 26.

Haag AM, Taylor SN, Johnston KH \& Cole RB (1998) Rapid identification and speciation of Haemophilus bacteria by matrix-assisted laser desorption/ionization time-of-flight mass spectrometry. J Mass Spectrom 33: 750-756.

Hathout Y, Ho YP, Ryzhov V, Demirev P \& Fenselau C (2000) Kurstakins: a new class of lipopeptides isolated from Bacillus thuringiensis. J Nat Prod 63: 1492-1496.

Hazen TH, Martinez RJ, Chen Y et al. (2009) Rapid identification of Vibrio parahaemolyticus by whole-cell matrix-assisted laser desorption ionization-time of flight mass spectrometry. Appl Environ Microbiol 75: 67456756.

Heller DN, Cotter RJ, Fenselau C \& Uy OM (1987) Profiling of bacteria by fast atom bombardment mass spectrometry. Anal Chem 59: 2806-2809.

Heller DN, Murphy CM, Cotter RJ, Fenselau C \& Uy OM (1988) Constant neutral loss scanning for the characterization of bacterial phospholipids desorbed by fast atom bombardment. Anal Chem 60: 2787-2791.

Hettick JM, Kashon ML, Simpson JP, Siegel PD, Mazurek GH \& Weissman DN (2004) Proteomic profiling of intact mycobacteria by matrix-assisted laser desorption/ionization time-of-flight mass spectrometry. Anal Chem 76: 5769-5776.

Hettick JM, Green BJ, Buskirk AD et al. (2008a)

Discrimination of Aspergillus isolates at the species and strain level by matrix-assisted laser desorption/ionization time-of-flight mass spectrometry fingerprinting. Anal Biochem 380: 276-281.

Hettick JM, Green BJ, Buskirk AD et al. (2008b) Discrimination of Penicillium isolates by matrix-assisted laser desorption/ionization time-of-flight mass spectrometry fingerprinting. Rapid Commun Mass Spectrom 22: 25552560.

Ho YP \& Fenselau C (1998) Applications of 1.06-micron IR laser desorption on a Fourier transform mass spectrometer. Anal Chem 70: 4890-4895.

Holland RD, Wilkes JG, Rafii F, Sutherland JB, Persons CC, Voorhees KJ \& Lay JO Jr (1996) Rapid identification of intact whole bacteria based on spectral patterns using matrixassisted laser desorption/ionization with time-of-flight mass spectrometry. Rapid Commun Mass Spectrom 10: 1227-1232.

Holland RD, Duffy CR, Rafii F et al. (1999) Identification of bacterial proteins observed in MALDI TOF mass spectra from whole cells. Anal Chem 71: 3226-3230.

Hsieh SY, Tseng CL, Lee YS, Kuo AJ, Sun CF, Lin YH \& Chen JK (2008) Highly efficient classification and identification of human pathogenic bacteria by MALDI-TOF MS. Mol Cell Proteomics 7: 448-456.

Jackson KA, Edwards-Jones V, Sutton CW \& Fox AJ (2005) Optimisation of intact cell MALDI method for fingerprinting of methicillin-resistant Staphylococcus aureus. J Microbiol Methods 62: 273-284.

Jonsson AP (2001) Mass spectrometry for protein and peptide characterisation. Cell Mol Life Sci 58: 868-884.

Karger A, Ziller M, Bettin B, Mintel B, Schares S \& Geue L (2011) Determination of serotypes of Shiga toxin-producing Escherichia coli isolates by intact cell matrix-assisted laser desorption ionization-time of flight mass spectrometry. Appl Environ Microbiol 77: 896-905.

Kawamura Y, Hou XG, Sultana F, Miura H \& Ezaki T (1995) Determination of $16 \mathrm{~S}$ rRNA sequences of Streptococcus mitis and Streptococcus gordonii and phylogenetic relationships among members of the genus Streptococcus. Int J Syst Bacteriol 45: 406-408.

Kemptner J, Marchetti-Deschmann M, Mach R, Druzhinina IS, Kubicek CP \& Allmaier G (2009) Evaluation of matrixassisted laser desorption/ionization (MALDI) preparation techniques for surface characterization of intact Fusarium spores by MALDI linear time-of-flight mass spectrometry. Rapid Commun Mass Spectrom 23: 877-884.

Kollef MH (2000) Inadequate antimicrobial treatment: an important determinant of outcome for hospitalized patients. Clin Infect Dis 31(suppl 4): S131-S138.

Krause E, Wenschuh H \& Jungblut PR (1999) The dominance of arginine-containing peptides in MALDI-derived tryptic mass fingerprints of proteins. Anal Chem 71: 4160-4165.

Krishnamurthy T \& Ross PL (1996) Rapid identification of bacteria by direct matrix-assisted laser desorption/ionization mass spectrometric analysis of whole cells. Rapid Commun Mass Spectrom 10: 1992-1996.

La Scola B \& Raoult D (2009) Direct identification of bacteria in positive blood culture bottles by matrix-assisted laser 
desorption ionisation time-of-flight mass spectrometry. PLOS ONE 4: e8041.

Lay JO Jr. (2001) MALDI-TOF mass spectrometry of bacteria. Mass Spectrom Rev 20: 172-194.

Lefmann M, Honisch C, Bocker S et al. (2004) Novel mass spectrometry-based tool for genotypic identification of mycobacteria. J Clin Microbiol 42: 339-346.

Leibovici L, Shraga I, Drucker M, Konigsberger H, Samra Z \& Pitlik SD (1998) The benefit of appropriate empirical antibiotic treatment in patients with bloodstream infection. J Intern Med 244: 379-386.

Li TY, Liu BH \& Chen YC (2000) Characterization of Aspergillus spores by matrix-assisted laser desorption/ ionization time-of-flight mass spectrometry. Rapid Commun Mass Spectrom 14: 2393-2400.

Liang X, Zheng K, Qian MG \& Lubman DM (1996) Determination of bacterial protein profiles by matrixassisted laser desorption/ionization mass spectrometry with high-performance liquid chromatography. Rapid Commun Mass Spectrom 10: 1219-1226.

Liu H, Du Z, Wang J \& Yang R (2007) Universal sample preparation method for characterization of bacteria by matrix-assisted laser desorption ionization-time of flight mass spectrometry. Appl Environ Microbiol 73: 1899-1907.

Lotz A, Ferroni A, Beretti JL et al. (2010) Rapid identification of mycobacterial whole cells in solid and liquid culture media by matrix-assisted laser desorption ionization-time of flight mass spectrometry. J Clin Microbiol 48: 44814486.

Madonna AJ, Basile F, Ferrer I, Meetani MA, Rees JC \& Voorhees KJ (2000) On-probe sample pretreatment for the detection of proteins above $15 \mathrm{KDa}$ from whole cell bacteria by matrix-assisted laser desorption/ionization time-of-flight mass spectrometry. Rapid Commun Mass Spectrom 14: 2220-2229.

Marinach-Patrice C, Lethuillier A, Marly A et al. (2009) Use of mass spectrometry to identify clinical Fusarium isolates. Clin Microbiol Infect 15: 634-642.

Marinach-Patrice C, Fekkar A, Atanasova R et al. (2010) Rapid species diagnosis for invasive candidiasis using mass spectrometry. PLoS ONE 5: e8862.

Marklein G, Josten M, Klanke U et al. (2009) Matrix-assisted laser desorption ionization-time of flight mass spectrometry for fast and reliable identification of clinical yeast isolates. J Clin Microbiol 47: 2912-2917.

Meetani MA, Shin YS, Zhang S, Mayer R \& Basile F (2007) Desorption electrospray ionization mass spectrometry of intact bacteria. J Mass Spectrom 42: 1186-1193.

Mellmann A, Cloud J, Maier T et al. (2008) Evaluation of matrix-assisted laser desorption ionization-time-of-flight mass spectrometry in comparison to $16 \mathrm{~S}$ rRNA gene sequencing for species identification of nonfermenting bacteria. J Clin Microbiol 46: 1946-1954.

Mellmann A, Bimet F, Bizet C et al. (2009) High interlaboratory reproducibility of matrix-assisted laser desorption ionization-time of flight mass spectrometry- based species identification of nonfermenting bacteria. J Clin Microbiol 47: 3732-3734.

Montero CI, Shea YR, Jones PA, Harrington SM, Tooke NE, Witebsky FG \& Murray PR (2008) Evaluation of pyrosequencing technology for the identification of clinically relevant non-dematiaceous yeasts and related species. Eur $J$ Clin Microbiol Infect Dis 27: 821-830.

Moussaoui W, Jaulhac B, Hoffmann AM, Ludes B, Kostrzewa M, Riegel P \& Prevost G (2010) Matrix-assisted laser desorption ionization time-of-flight mass spectrometry identifies $90 \%$ of bacteria directly from blood culture vials. Clin Microbiol Infect 16: 1631-1638.

Munson EL, Diekema DJ, Beekmann SE, Chapin KC \& Doern GV (2003) Detection and treatment of bloodstream infection: laboratory reporting and antimicrobial management. J Clin Microbiol 41: 495-497.

Murray PR (2010) Matrix-assisted laser desorption ionization time-of-flight mass spectrometry: usefulness for taxonomy and epidemiology. Clin Microbiol Infect 16: 1626-1630.

Nagy E, Maier T, Urban E, Terhes G \& Kostrzewa M (2009) Species identification of clinical isolates of Bacteroides by matrix-assisted laser-desorption/ionization time-of-flight mass spectrometry. Clin Microbiol Infect 15: 796802.

Nyvang Hartmeyer G, Kvistholm Jensen A, Bocher S et al. (2010) Mass spectrometry: pneumococcal meningitis verified and Brucella species identified in less than half an hour. Scand J Infect Dis 42: 716-718.

Pignone M, Greth KM, Cooper J, Emerson D \& Tang J (2006) Identification of mycobacteria by matrix-assisted laser desorption ionization-time-of-flight mass spectrometry. J Clin Microbiol 44: 1963-1970.

Pineda FJ, Lin JS, Fenselau C \& Demirev PA (2000) Testing the significance of microorganism identification by mass spectrometry and proteome database search. Anal Chem 72: 3739-3744.

Platt JA, Uy OM, Heller DN, Cotter RJ \& Fenselau C (1988) Computer-based linear regression analysis of desorption mass spectra of microorganisms. Anal Chem 60: 14151419.

Pribil P \& Fenselau C (2005) Characterization of Enterobacteria using MALDI-TOF mass spectrometry. Anal Chem 77: 6092-6095.

Prod'hom G, Bizzini A, Durussel C, Bille J \& Greub G (2010) Matrix-assisted laser desorption ionization-time of flight mass spectrometry for direct bacterial identification from positive blood culture pellets. J Clin Microbiol 48: 14811483.

Romero-Gomez MP \& Mingorance J (2011) The effect of the blood culture bottle type in the rate of direct identification from positive cultures by matrix-assisted laser desorption/ ionisation time-of-flight (MALDI-TOF) mass spectrometry. $J$ Infect 62: 251-253.

Ruelle V, El Moualij B, Zorzi W, Ledent P \& Pauw ED (2004) Rapid identification of environmental bacterial strains by matrix-assisted laser desorption/ionization time-of-flight 
mass spectrometry. Rapid Commun Mass Spectrom 18: 2013-2019.

Rupf S, Breitung K, Schellenberger W, Merte K, Kneist S \& Eschrich K (2005) Differentiation of mutans streptococci by intact cell matrix-assisted laser desorption/ionization timeof-flight mass spectrometry. Oral Microbiol Immunol 20: 267-273.

Ryzhov V \& Fenselau C (2001) Characterization of the protein subset desorbed by MALDI from whole bacterial cells. Anal Chem 73: 746-750.

Saenz AJ, Petersen CE, Valentine NB, Gantt SL, Jarman KH, Kingsley MT \& Wahl KL (1999) Reproducibility of matrixassisted laser desorption/ionization time-of-flight mass spectrometry for replicate bacterial culture analysis. Rapid Commun Mass Spectrom 13: 1580-1585.

Schabereiter-Gurtner C, Selitsch B, Rotter ML, Hirschl AM \& Willinger B (2007) Development of novel real-time PCR assays for detection and differentiation of eleven medically important Aspergillus and Candida species in clinical specimens. J Clin Microbiol 45: 906-914.

Seng P, Drancourt M, Gouriet F, La Scola B, Fournier PE, Rolain JM \& Raoult D (2009) Ongoing revolution in bacteriology: routine identification of bacteria by matrixassisted laser desorption ionization time-of-flight mass spectrometry. Clin Infect Dis 49: 543-551.

Seyfarth F, Ziemer M, Sayer HG et al. (2008) The use of ITS DNA sequence analysis and MALDI-TOF mass spectrometry in diagnosing an infection with Fusarium proliferatum. Exp Dermatol 17: 965-971.

Shah HN \& Collins MD (1980) Fatty acid and isoprenoid quinone composition in the classification of Bacteroides melaninogenicus and related taxa. J Appl Bacteriol 48: 75-87.

She YM, Haber S, Seifers DL et al. (2001) Determination of the complete amino acid sequence for the coat protein of brome mosaic virus by time-of-flight mass spectrometry. Evidence for mutations associated with change of propagation host. J Biol Chem 276: 20039-20047.

Siegrist TJ, Anderson PD, Huen WH, Kleinheinz GT, McDermott CM \& Sandrin TR (2007) Discrimination and characterization of environmental strains of Escherichia coli by matrix-assisted laser desorption/ionization time-of-flight mass spectrometry (MALDI-TOF-MS). J Microbiol Methods 68: $554-562$.

Spanu T, De Carolis E, Fiori B, Sanguinetti M, D’Inzeo T, Fadda G \& Posteraro B (2011) Evaluation of matrix-assisted laser desorption ionization-time-of-flight mass spectrometry in comparison to $\mathrm{rpoB}$ gene sequencing for species identification of bloodstream infection staphylococcal isolates. Clin Microbiol Infect 17: 44-49.

Speers DJ, Olma TR \& Gilbert GL (1998) Evaluation of four methods for rapid identification of Staphylococcus aureus from blood cultures. J Clin Microbiol 36: 10321034.

Stevenson LG, Drake SK \& Murray PR (2010a) Rapid identification of bacteria in positive blood culture broths by matrix-assisted laser desorption ionization-time of flight mass spectrometry. J Clin Microbiol 48: 444447.

Stevenson LG, Drake SK, Shea YR, Zelazny AM \& Murray PR (2010b) Evaluation of matrix-assisted laser desorption ionization-time of flight mass spectrometry for identification of clinically important yeast species. J Clin Microbiol 48: 3482-3486.

Suh MJ \& Limbach PA (2004) Investigation of methods suitable for the matrix-assisted laser desorption/ionization mass spectrometric analysis of proteins from ribonucleoprotein complexes. Eur J Mass Spectrom (Chichester, Eng) 10: 89-99.

Sun L, Teramoto K, Sato H, Torimura M, Tao H \& Shintani T (2006) Characterization of ribosomal proteins as biomarkers for matrix-assisted laser desorption/ionization mass spectral identification of Lactobacillus plantarum. Rapid Commun Mass Spectrom 20: 3789-3798.

Szabados F, Michels M, Kaase M \& Gatermann S (2011) The sensitivity of direct identification from positive BacT/ALERT (bioMerieux) blood culture bottles by matrix-assisted laser desorption ionization time-of-flight mass spectrometry is low. Clin Microbiol Infect 17: 192-195.

Tanaka K \& Fenn JB (2002) Nobel Laureates in chemistry. Available at http://www.nobelprize.org

Teramoto K, Sato H, Sun L et al. (2007) Phylogenetic classification of Pseudomonas putida strains by MALDI-MS using ribosomal subunit proteins as biomarkers. Anal Chem 79: $8712-8719$.

Vaidyanathan S, Winder CL, Wade SC, Kell DB \& Goodacre R (2002) Sample preparation in matrix-assisted laser desorption/ionization mass spectrometry of whole bacterial cells and the detection of high mass $(>20 \mathrm{kDa})$ proteins. Rapid Commun Mass Spectrom 16: 1276-1286.

Valentine NB, Wahl JH, Kingsley MT \& Wahl KL (2002) Direct surface analysis of fungal species by matrix-assisted laser desorption/ionization mass spectrometry. Rapid Commun Mass Spectrom 16: 1352-1357.

Valentine N, Wunschel S, Wunschel D, Petersen C \& Wahl K (2005) Effect of culture conditions on microorganism identification by matrix-assisted laser desorption ionization mass spectrometry. Appl Environ Microbiol 71: 58-64.

Vargha M, Takats Z, Konopka A \& Nakatsu CH (2006) Optimization of MALDI-TOF MS for strain level differentiation of Arthrobacter isolates. J Microbiol Methods 66: 399-409.

van Veen SQ, Claas EC \& Kuijper EJ (2010) High-throughput identification of bacteria and yeast by matrix-assisted laser desorption ionization-time of flight mass spectrometry in conventional medical microbiology laboratories. J Clin Microbiol 48: 900-907.

Walker J, Fox AJ, Edwards-Jones V \& Gordon DB (2002) Intact cell mass spectrometry (ICMS) used to type methicillin-resistant Staphylococcus aureus: media effects and inter-laboratory reproducibility. J Microbiol Methods 48: $117-126$. 
Wang ZP, Russon L, Li L, Roser DC \& Long SR (1998) Investigation of spectral reproducibility in direct analysis of bacteria proteins by matrix-assisted laser desorption/ ionization time-of-flight mass spectrometry. Rapid Commun Mass Spectrom 12: 456-464.

Welham KJ, Domin MA, Scannell DE, Cohen E \& Ashton DS (1998) The characterization of micro-organisms by matrixassisted laser desorption/ionization time-of-flight mass spectrometry. Rapid Commun Mass Spectrom 12: 176-180.

Welham KJ, Domin MA, Johnson K, Jones L \& Ashton DS (2000) Characterization of fungal spores by laser desorption/ionization time-of-flight mass spectrometry. Rapid Commun Mass Spectrom 14: 307-310.

Williams TL, Andrzejewski D, Lay JO \& Musser SM (2003) Experimental factors affecting the quality and reproducibility of MALDI TOF mass spectra obtained from whole bacteria cells. J Am Soc Mass Spectrom 14: 342-351.

Wolters M, Rohde H, Maier T et al. (2011) MALDI-TOF MS fingerprinting allows for discrimination of major methicillin-resistant Staphylococcus aureus lineages. Int J Med Microbiol 301: 64-68.

Wunschel SC, Jarman KH, Petersen CE et al. (2005) Bacterial analysis by MALDI-TOF mass spectrometry: an interlaboratory comparison. J Am Soc Mass Spectrom 16: 456462.
Wybo I, De Bel A, Soetens O, Echahidi F, Vandoorslaer K, Van Cauwenbergh M \& Pierard D (2011) Differentiation of cfiA-negative and cfiA-positive Bacteroides fragilis isolates by matrix-assisted laser desorption ionization-time of flight mass spectrometry. J Clin Microbiol 49: 1961-1964.

\section{Supporting information}

Additional Supporting Information may be found in the online version of this article:

Fig. S1. Maintenance of MALDI-TOF mass spectrometer. Table S1. Summarized characteristics of several types of mass analysers.

Table S2. Costs savings due to MALDI-TOF MS by reduced need of conventional identification methods.

Box S1. Hardwares and softwares.

Please note: Wiley-Blackwell is not responsible for the content or functionality of any supporting materials supplied by the authors. Any queries (other than missing material) should be directed to the corresponding author for the article. 